\title{
The Roles of Biomarkers of Oxidative Stress and Antioxidant in Alzheimer's Disease: A Systematic Review
}

\author{
Ya-Ting Chang, ${ }^{1,2}$ Wen-Neng Chang, ${ }^{1}$ Nai-Wen Tsai, ${ }^{1}$ Chih-Cheng Huang, \\ Chia-Te Kung, ${ }^{3}$ Yu-Jih Su, ${ }^{2,4}$ Wei-Che Lin, ${ }^{5}$ Ben-Chung Cheng, ${ }^{2,4}$ Chih-Min Su, ${ }^{2,4}$ \\ Yi-Fang Chiang, ${ }^{1}$ and Cheng-Hsien $\mathrm{Lu}^{1,2,3}$
}

\author{
${ }^{1}$ Department of Neurology, Chang Gung Memorial Hospital-Kaohsiung Medical Center, Chang Gung University College of Medicine, \\ 123 Ta Pei Road, Niao Sung District, Kaohsiung 833, Taiwan \\ ${ }^{2}$ Department of Biological Science, National Sun Yat-Sen University, Kaohsiung 80424, Taiwan \\ ${ }^{3}$ Department of Emergency Medicine, Chang Gung Memorial Hospital-Kaohsiung Medical Center, \\ Chang Gung University College of Medicine, 123 Ta Pei Road, Niao Sung District, Kaohsiung 833, Taiwan \\ ${ }^{4}$ Department of Medicine, Chang Gung Memorial Hospital-Kaohsiung Medical Center, Chang Gung University College of Medicine, \\ 123 Ta Pei Road, Niao Sung District, Kaohsiung 833, Taiwan \\ ${ }^{5}$ Department of Radiology, Chang Gung Memorial Hospital-Kaohsiung Medical Center, Chang Gung University College of Medicine, \\ 123 Ta Pei Road, Niao Sung District, Kaohsiung 833, Taiwan
}

Correspondence should be addressed to Cheng-Hsien Lu; chlu99@ms44.url.com.tw

Received 25 February 2014; Accepted 27 March 2014; Published 14 May 2014

Academic Editor: Hung-Chen Wang

Copyright (C) 2014 Ya-Ting Chang et al. This is an open access article distributed under the Creative Commons Attribution License, which permits unrestricted use, distribution, and reproduction in any medium, provided the original work is properly cited.

\begin{abstract}
Purpose. Oxidative stress plays an important role in the pathogenesis of Alzheimer's disease (AD). This paper aims to examine whether biomarkers of oxidative stress and antioxidants could be useful biomarkers in AD, which might form the bases of future clinical studies. Methods. PubMed, SCOPUS, and Web of Science were systematically queried to obtain studies with available data regarding markers of oxidative stress and antioxidants from subjects with AD. Results and Conclusion. Although most studies show elevated serum markers of lipid peroxidation in $\mathrm{AD}$, there is no sufficient evidence to justify the routine use of biomarkers as predictors of severity or outcome in AD.
\end{abstract}

\section{Introduction}

Alzheimer's disease is the most common form of dementia in the elderly and is characterized by a progressive loss of cognitive capacity and severe neurodegeneration. The pathophysiologic process is posited to be initiated by extracellular fibrillary $\beta$-amyloid deposition, with subsequent intraneuronal hyperphosphorylated tau protein aggregation [1]. Mutations in the amyloid precursor protein (APP), presenilin-1 (PS1), or PS2 that alter APP metabolism favor the production of a fibrillary form, $A \beta$. Such findings form the basis of the amyloid cascade hypothesis of AD pathophysiology [2].

Although this amyloid cascade hypothesis may be the underlying pathogenesis for the familial form of $\mathrm{AD}$, increasing evidence suggests that oxidative stress has a key role in late-onset sporadic forms, which are the majority of $\mathrm{AD}$ cases. Abnormal levels of oxidative stress have been reported in Alzheimer's disease in both the brain and blood stream $[3,4]$. Changes in Alzheimer's disease that produce a prooxidative imbalance have been attributed to decrease in antioxidant defenses, toxicity related to amyloid- $\beta$, and/or altered metal metabolism in the brain and peripheral tissues $[3,4]$ (Figure 1).

Oxidative stress, a pathophysiologic imbalance between oxidants and antioxidants in favor of the former, with potential damage, has been shown in the blood, cerebrospinal fluid (CSF), and brain of neurologic patients with probable $\mathrm{AD}$ [5-12]. Biomarkers of oxidative stress in subjects with $\mathrm{AD}$ are classified as lipid peroxidation, protein oxidation, DNA oxidation, superoxide dismutase, and glutathione system $[5,13-16]$. Biomarkers of oxidative damage to lipids 


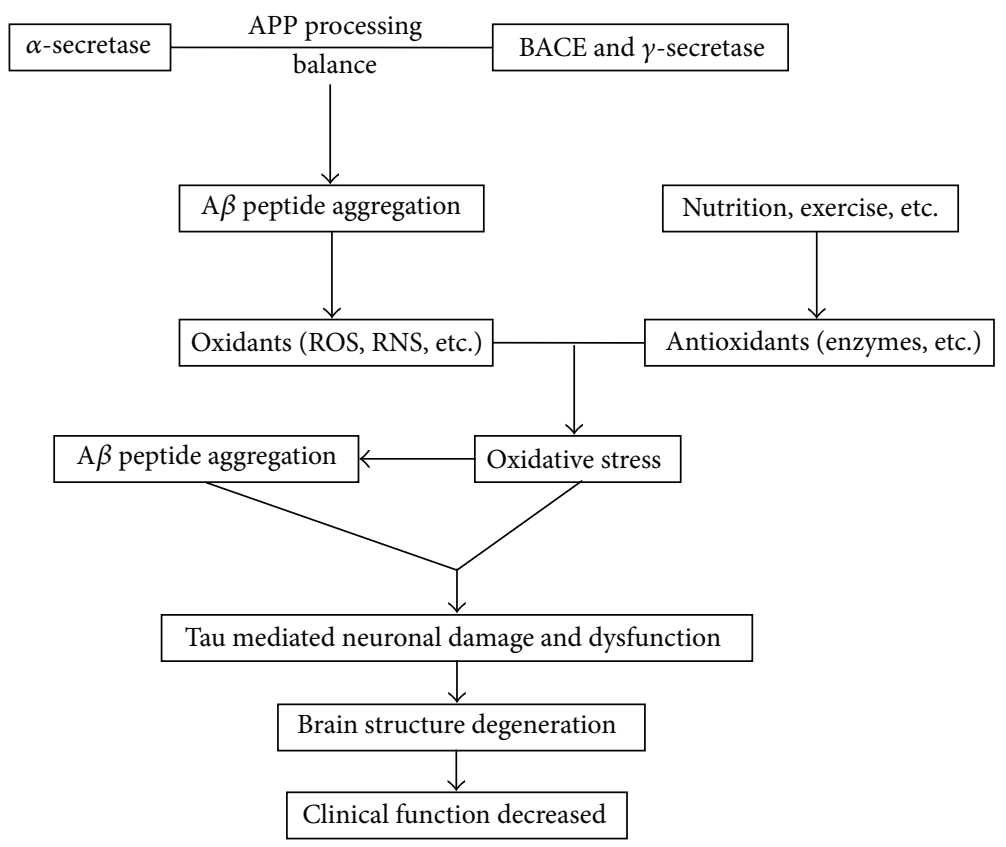

FIgURE 1: Oxidative stress in Alzheimer's dementia. APP: amyloid precursor protein; BACE: beta-secretase; ROS: reactive oxygen species; RNS: reactive nitrogen species; $\mathrm{A} \beta$ : amyloid $\beta$.

include thiobarbituric acid-reactive substances (TBARS) and oxidized-LDL (ox-LDL) [7, 17]. The level of TBARS can be measured in plasma, serum, erythrocytes, and leukocytes [7], while ox-LDL is mostly measured in serum [17]. Oxidative attack on proteins results in the formation of protein carbonyls and protein nitration $[18,19]$. Protein carbonyls and nitrated protein can be measured in plasma, serum, CSF, and brain tissue [18]. Regarding nucleic acids, 8-hydroxy2-deoxyguanosine (8-OHdG) is one of the most commonly used markers of oxidative nucleic acid damage and can be measured in lymphocytes, leukocytes, and the brain [16].

The possible benefits of biomarkers in clinical practice include outcome prediction in $\mathrm{AD}$ patients that may further influence therapeutic regimens. The aim of this review is to determine whether biomarkers of oxidative stress can play an important prognostic role in the outcome of $\mathrm{AD}$. The successful translation of these approaches to the clinics offers the promise of not only improving outcome prediction but also a more scientific basis for therapeutic options.

\section{Methods}

Studies were identified from a systematic search of PubMed, Scopus databases, Google Scholar, and the reference lists of all included studies and major relevant review papers. To find all of the relevant articles, PubMed was searched using the key words: "TBARS," "oxidized LDL," "protein carbonyls," "8-HOG," "antioxidant," and "Alzheimer's disease" in various combinations. Case-control studies with human subjects were considered for inclusion. The articles selected were published in English between January 1985 and September 2013.

\section{Results}

3.1. Biomarkers of Lipid Peroxidation. Lipid peroxidation is one of the major consequences of oxidative imbalancemediated injury to the brain. It causes changes in the fluidity and permeability of cell membranes and impairs the activity of membrane-bound enzymes. Lipid peroxidation also leads to the production of conjugated diene hydroperoxides and unstable substances that disintegrate into various aldehydes like malondialdehyde, 4-hydroxynonenal, and TBARS.

Several studies demonstrate that serum or plasma TBARS level in AD subjects is significantly higher than in controls [7, $13,15,20-28]$, while others observe no significant difference between AD subjects and controls [29-35] (Table 1). Results regarding erythrocyte TBARS level in $\mathrm{AD}$ are also controversial. Some studies observe higher erythrocyte TBARS levels in $\mathrm{AD}[5,7,31]$, while others observe no difference between $\mathrm{AD}$ and controls [6, 15, 29, 36]. A meta-analysis regarding blood TBARS level in $\mathrm{AD}$ and mild cognitive impairment reveals that TBARS levels are significantly elevated in Alzheimer's disease plasma/serum [37]. However, findings may vary by different patients selection criteria: some researchers observe AD subjects with MMSE 7-24 points do not have significantly higher serum TBARS than controls [34], while others observe AD subjects with 7-20 points as well as ADAS-cog 10-35 points have significantly higher serum TBARS than controls [20]. These suggest that MMSE alone is not enough to discriminate those with higher TBARS from those with lower TBARS. The lack of a link between MMSE and TBARS is also reported by another study, which suggests that MMSE is not correlated with TBARS [7], while plasma TBARS level may actually increase with the severity of cognitive dysfunction in $\mathrm{AD}[7]$. 
TABLE 1: Studies exploring the predictive capacity of biomarkers of lipid peroxidation in AD.

\begin{tabular}{|c|c|c|c|}
\hline Reference & Subjects' characteristic & Specimen & Results \\
\hline \multicolumn{4}{|c|}{ TBARS } \\
\hline $\begin{array}{l}\text { Aybek et al. } \\
(2007)[20]\end{array}$ & $\begin{array}{l}62 \mathrm{AD} \text { pts (mean age }=73.3 \text {, MMSE of } 7 \text { to } \\
20 \text { points, ADAS-Cog of } 10 \text { to } 35 \text { points, } \\
\text { GDS }>1 \text { and } \leq 3 \text { ). } 56 \text { controls (mean age }= \\
70.8 \text { ). }\end{array}$ & Serum & $\begin{array}{l}\text { Significantly higher in } \mathrm{AD} \text { patients and control } \\
\text { group (Mann-Whitney } U \text { test, } P=0.0001 \text { ). }\end{array}$ \\
\hline $\begin{array}{l}\text { Casado et al. } \\
(2008)[5]\end{array}$ & $\begin{array}{l}50 \text { AD pts ( } 22 \text { pts aged from } 65 \text { to } 74,23 \text { pts } \\
\text { aged of } 75 \text { to } 84 \text {, five pts aged }>85 \text { ). } \\
\text { Exclusion criteria: DM, myeloproliferative } \\
\text { disorders, uncontrolled hypertension, } \\
\text { mental retardation, malnutrition. } 50 \\
\text { controls ( } 24 \text { subjects age of } 65 \text { to } 74,21 \\
\text { subjects age of } 75 \text { to } 84 \text {, five subjects age }>85 \text {. }\end{array}$ & $\begin{array}{l}\text { Erythrocytes } \\
\text { (HPLC) }\end{array}$ & $\begin{array}{l}\text { Significantly higher in } \mathrm{AD} \text { within group aged } \\
65-74 \text { years }(P<0.001) \text {, group aged } 75-84 \\
\text { years }(P<0.001) \text {, and group aged } 85-94 \text { years } \\
(P<0.05) .\end{array}$ \\
\hline $\begin{array}{l}\text { Bermejo et al. } \\
(1997)[13]\end{array}$ & $\begin{array}{l}18 \text { AD pts }(\text { mean age }=76.3) .14 \text { controls } \\
(\text { mean age }=75.2)\end{array}$ & $\begin{array}{l}\text { Erythrocytes } \\
\text { (HPLC) }\end{array}$ & Significantly higher in $\operatorname{AD}(P<0.01)$. \\
\hline $\begin{array}{l}\text { Ceballos- } \\
\text { Picot et al. } \\
(1996)[31]\end{array}$ & $\begin{array}{l}40 \mathrm{AD} \text { pts (mean age }=84.2 \text { ). Exclusion } \\
\text { criteria: life expectancy less than } 4 \text { months, } \\
\text { taking steroids, blindness, or deafness. } 34 \\
\text { controls (mean age }=79.1 \text { ). }\end{array}$ & Plasma & $\begin{array}{l}\text { No significant difference between } \mathrm{AD} \text { and } \\
\text { controls. }\end{array}$ \\
\hline $\begin{array}{l}\text { Gironi et al. } \\
\text { (2011) [32] }\end{array}$ & $\begin{array}{l}25 \mathrm{AD} \text { pts (mean age }=78.2 \text { ). Exclusion } \\
\text { criteria: vascular insult, DM, chronic } \\
\text { infection, malignant disease, severe renal, } \\
\text { hepatic cardiorespiratory or hematological } \\
\text { disease, and use of vitamin supplementation. } \\
66 \text { controls (mean age }=70.4 \text { ). }\end{array}$ & Serum & $\begin{array}{l}\text { No significant difference between } \mathrm{AD} \text { and } \\
\text { controls. }\end{array}$ \\
\hline $\begin{array}{l}\text { McGrath et al. } \\
(2001)[34]\end{array}$ & $\begin{array}{l}29 \mathrm{AD} \text { pts (mean age }=74 \text {, MMSE of } 7 \text { to } 24 \text { ). } \\
\text { Exclusion criteria: other significant medical } \\
\text { problems. } 46 \text { controls (mean age } 73 \text { ). }\end{array}$ & Serum & $\begin{array}{l}\text { No significant difference between } \mathrm{AD} \text { and } \\
\text { controls. }\end{array}$ \\
\hline
\end{tabular}

$27 \mathrm{AD}$ pts (mean age $=72.3$ ). Exclusion

Ozcankaya criteria: life expectancy less than 3 months, and Delibas taking steroids, blindness and deafness, iron (2002) [21] for anemia, illiterate patients, and medical disorder other than dementia. 25 controls (mean age $=64.4$ ).

112 AD pts (mean age $=72.1)$. Exclusion criteria: head trauma, seizures, uncontrolled Serra et al. hypertension, mental retardation, psychosis (2009) [22] or depression, smoking within 5 years, and vascular insult. Inclusion: GDS of 3 to 5.80 controls (mean age $=68.4$ ).

Torres et al. (2011) [24] 29 AD pts. 26 controls.

Serum

MMSE was negatively associated with MDA levels $(r=-0.31, P=0.028)$. Significantly higher in $\mathrm{AD}(P<0.05)$.

Significantly higher in mild, intermediate, and severe $\mathrm{AD}$ in comparison with control in

Cristalli et al. $110 \mathrm{AD}$ pts (mean age $=74.7$, GDS $3=$ mild, (2012) [7] No further exclusion criteria. 134 controls (mean age $=77.8$ ).

Plasma/ erythrocyte/ leukocytes plasma, erythrocytes and leukocytes samples. Significantly higher in severe AD in comparison with mild and intermediate $\mathrm{AD}$ in especially erythrocytes and leukocytes samples. Not inversely correlated with MMSE.

20 AD pts (mean age $=80.1$ ). Follow-up at

BourdelMarchasson et al. (2001) [15] memory center for more than 6 months, no evidence of nutritional behavior, mean duration of $\mathrm{AD}$ was 3.9 years, 19 pts on cholinergic therapy. 23 controls, mean age
Plasma/ erythrocytes
Significantly higher in $\mathrm{AD}$ in plasma level $(P=0.036)$. No significant difference between $\mathrm{AD}$ and control in erythrocytes level. 
TABle 1: Continued.

\begin{tabular}{|c|c|c|c|}
\hline Reference & Subjects' characteristic & Specimen & Results \\
\hline $\begin{array}{l}\text { Polidori et al. } \\
(2002)[25]\end{array}$ & $\begin{array}{l}35 \mathrm{AD} \text { pts }(\text { mean age }=85.9) .40 \text { controls } \\
(\text { mean age }=85.5) .\end{array}$ & Plasma & $\begin{array}{l}\text { Significantly higher in AD in plasma level } \\
(P<0.001) \text {. }\end{array}$ \\
\hline $\begin{array}{l}\text { Sekler et al. } \\
(2008)[35]\end{array}$ & $\begin{array}{l}59 \mathrm{AD} \text { pts }(\text { mean age }=76.4, \mathrm{MMSE}= \\
14.1 \pm 6.0) .29 \text { controls }(\text { mean age }=70.7) .\end{array}$ & Plasma & $\begin{array}{l}\text { No significant difference between } \mathrm{AD} \text { and } \\
\text { controls. }\end{array}$ \\
\hline $\begin{array}{l}\text { Serra et al. } \\
(2001)[6]\end{array}$ & 18 AD pts. 14 controls. & Erythrocytes & $\begin{array}{l}\text { No significant difference between } \mathrm{AD} \text { and } \\
\text { controls. }\end{array}$ \\
\hline $\begin{array}{l}\text { Padurariu } \\
\text { et al. }(2010) \\
{[26]}\end{array}$ & $\begin{array}{l}15 \mathrm{AD} \text { pts (mean age }=65.8, \mathrm{MMSE}= \\
18.5 \pm 0.3, \mathrm{ADAS}-\mathrm{cog}=18.5 \pm 0.3, \text { not } \\
\text { taking antioxidant supplement). } 15 \text { controls } \\
\text { (mean age }=62.5)\end{array}$ & Serum & $\begin{array}{l}\text { Significantly higher in AD in serum level } \\
(P<0.0005) .\end{array}$ \\
\hline \multirow[t]{2}{*}{$\begin{array}{l}\text { Puertas et al. } \\
(2012)[28]\end{array}$} & $\begin{array}{l}\text { 20 AD men (mean age }=70.6, \text { MMSE } \\
23.7 \pm 0.92) .26 \mathrm{AD} \text { women (mean age }= \\
73.9 \text {, MMSE } 20.7 \pm 0.66) . \text { Exclusion criteria: } \\
\text { taking NSAIDs, steroids, vitamins or } \\
\text { antioxidant supplements, history of smoking } \\
\text { and alcohol intake, and comorbidity with } \\
\text { other clinical major neurological illnesses. } 16 \\
\text { control men (mean age }=73.3 .30 \text { control } \\
\text { women (mean age }=73.8) .\end{array}$ & Plasma & $\begin{array}{l}\text { Significantly higher in both male and female } \\
\text { AD individuals in plasma level }(P<0.01) \text {. }\end{array}$ \\
\hline & Ox-LDL & & \\
\hline $\begin{array}{l}\text { Aldred et al. } \\
(2010)[17]\end{array}$ & $\begin{array}{l}72 \mathrm{AD} \text { pts }(\text { mean age }=80, \mathrm{AD} \text { Geriatric } \\
\text { depression scale }=7.4 \pm 3.6, \mathrm{MMSE}= \\
19 \pm 4.72) . \text { Controls }(\text { mean age }=75) .\end{array}$ & Serum & Significantly higher in $\operatorname{AD}(P=0.05)$. \\
\hline $\begin{array}{l}\text { Cai et al. } \\
(2007)[40]\end{array}$ & 15 AD pts. 15 controls. & Serum & $\begin{array}{l}\text { Significantly higher in } \mathrm{AD}(P<0.05) \text {. MMSE } \\
\text { inversely correlated with ox-LDL }(P<0.05) .\end{array}$ \\
\hline
\end{tabular}

Ox-LDL has been suggested to be produced by oxidized phospholipids released from brain tissue into circulation [38]. Ox-LDL is a promising marker of oxidative injury of the whole body. It may also be a peripheral marker that is linked to the severity of oxidative damage in the presence of dementia $[23,39,40]$. Serum ox-LDL level is universally higher in $\mathrm{AD}$ than in controls in the three studies.

3.2. Biomarkers of Protein Oxidation. Two different biomarkers of free-radical damage against protein have been suggested: protein oxidation that leads to the production of protein carbonyls $[7,14,17,18,23,28,40-47]$ and protein peroxidation that leads to the production of nitrated protein $[18,19,43,46,48-50]$ (Table 2). As a peripheral marker of oxidative stress in the brain, higher serum/plasma protein carbonyls level in $\mathrm{AD}$ is demonstrated in several studies despite varying patient selection criteria $[7,18,40-$ $43,46]$. Only two studies show no significant difference in serum/plasma protein carbonyls level between $\mathrm{AD}$ and controls $[17,23]$.

3.3. Biomarkers of Antioxidants. Antioxidants are suggested as potential indirect markers of oxidative stress processing in the brain of patients with AD (Table 3). Oxidative stress has been speculated to cause antioxidant consumption and thus, a decline in antioxidant levels [51]. Nonenzymatic compounds with antioxidant properties include vitamin A/carotenoids, vitamins $\mathrm{C}$ and $\mathrm{E}$, and uric acid. On the other hand, antioxidant enzymes that vary on condition of oxidative stress in $\mathrm{AD}$ remain unsettled, since antioxidant enzymes like glutathione peroxidase $(\mathrm{GPx})$ and superoxide dismutase (SOD) may be induced by oxidative stress (to increase their level or activity) or consumed (to decrease their level or activity) [37].

3.3.1. Uric Acid. Three studies elaborate that plasma or serum uric acid level is significantly lower in $\mathrm{AD}$ [52-54], while three other studies do not observe this difference $[29,55,56]$. It is possible that excluding patients with metabolic syndrome plays an important role in measurements of significantly lower uric acid level in $\mathrm{AD}[52,54]$. This suggests that metabolic syndrome may interfere with the level of uric acid as an indirect marker of oxidative stress in $\mathrm{AD}$.

3.3.2. Vitamin E. Most of the studies in the literature report that plasma or serum vitamin E level is significantly lower in $\mathrm{AD}[7,9,10,15,16,25,54,57-60]$. However, vitamin $\mathrm{E}$ supplementation does not seem to improve prognosis in $\mathrm{AD}$ [61]. So far, erythrocyte and platelet vitamin E levels are not different between AD and controls [15, 29].

3.3.3. Vitamin C. Vitamin C concentration in plasma or serum is also found to be significantly lower in $\mathrm{AD}$ in most literature $[10,16,25,54,60,62,63]$. Furthermore, vitamin $\mathrm{C}$ is especially significantly lower in moderate and severe AD [62].

3.3.4. Vitamin A. All of the studies on serum or plasma vitamin A levels establish a significant difference between $A D$ and control $[10,16,25,54,63,64]$. 
TABLE 2: Studies exploring the predictive capacity of biomarkers of protein peroxidation in AD.

\begin{tabular}{llcl}
\hline Reference & Subjects' characteristic & Specimen & Results \\
\hline & & Protein carbonyls &
\end{tabular}

Significantly higher in mild, intermediate, and

$110 \mathrm{AD}$ pts (mean age $=74.7$, GDS $3=$ mild,

Cristalli et al. GDS 4-5 = intermediate, GDS 6-7 = severe).

(2012) [7] No further exclusion criteria. 134 controls (mean age $=77.8$ ). severe $\mathrm{AD}$ in comparison with control in plasma, erythrocytes, and leukocytes samples.

plasma/ erythrocyte/ leukocytes Significantly higher in severe AD than intermediate $\mathrm{AD}$ and in intermediate $\mathrm{AD}$ than mild AD in plasma, erythrocytes, and leukocytes samples. Inversely correlated with MMSE in all kind of samples.

\begin{tabular}{|c|c|c|c|}
\hline $\begin{array}{l}\text { Bermejo et al. } \\
(2008)[41]\end{array}$ & 45 AD pts. 28 controls. & Serum & Significantly higher in $\mathrm{AD}(P<0.05)$. \\
\hline $\begin{array}{l}\text { Conrad et al. } \\
(2000)[42]\end{array}$ & $\begin{array}{l}25 \mathrm{AD} \text { pts }(\text { mean age }=78) .14 \text { controls } \\
(\text { mean age }=84) .\end{array}$ & Serum (HPLC) & Significantly higher in $\mathrm{AD}(P<0.05)$. \\
\hline $\begin{array}{l}\text { Aldred et al. } \\
(2010)[17]\end{array}$ & $\begin{array}{l}72 \mathrm{AD} \text { pts }(\text { mean age }=80, \mathrm{AD} \text { GDS }= \\
7.4 \pm 3.6, \mathrm{MMSE}=19 \pm 4) .72 \text { controls (mean } \\
\text { age }=75)\end{array}$ & Serum & No significant difference between $\mathrm{AD}$ and NC. \\
\hline $\begin{array}{l}\text { Cai et al. } \\
(2007)[40]\end{array}$ & 15 AD pts. 15 controls. & Serum & $\begin{array}{l}\text { Significantly higher in AD }(P<0.05) . \text { MMSE } \\
\text { inversely correlated with ox-LDL }(P<0.05) \text {. }\end{array}$ \\
\hline
\end{tabular}

$20 \mathrm{AD}$ men (mean age $=70.6$, MMSE

$23.7 \pm 0.92) .26 \mathrm{AD}$ women (mean age $=$ 73.9, MMSE $20.7 \pm 0.66$ ). Exclusion criteria:

Puertas et al. taking NSAIDs, steroids, vitamins or (2012) [28] taking NSAIDs, steroids, vitamins or
antioxidant supplements, history of smoking and alcohol intake, and comorbidity with Significantly higher in both male and female other clinical major neurological illnesses. 16 control men (mean age $=73.3 .30 \mathrm{control}$ women (mean age $=73.8$ ).

Sultana et al. $6 \mathrm{AD}$ pts (mean age at death $=84.5$, (2006) [43] MMSE $=15.7 \pm 2.6$ ). 6 controls (mean age at Brain: hippocampus death $=85.8)$

Castegna et al. $\quad 5 \mathrm{AD}$ pts (mean age at death $=85.5) .5$ (2002) [47] controls (mean age at death $=83$ ).

\section{Brain: neocortical,} hippocampal, entorhinal, amygdala, brainstem, and cerebellum

All identified proteins with protein carbonyls significantly higher in $\mathrm{AD}(P \leq 0.05)$.
All identified proteins with protein carbonyls significantly higher in $\mathrm{AD}(P \leq 0.05)$. AD individuals in serum level $(P<0.05)$.

\begin{tabular}{|c|c|c|c|}
\hline \\
\hline $\begin{array}{l}\text { Korolainen and } \\
\text { Pirttilä (2009) [18] }\end{array}$ & $\begin{array}{l}22 \mathrm{AD} \text { pts (mean age }=72,22 \mathrm{AD} \text { pts disease } \\
\text { duration }=2.3 \pm 0.3, \mathrm{MMSE}=21.3 \pm 0.9,12 \\
\mathrm{AD} \text { pts APOE } 4 \text { positive). } 10 \text { control APOE } 4 \\
\text { positive. } 18 \text { controls (mean age }=68 \text { ) }\end{array}$ & $\begin{array}{l}\text { CSF/ } \\
\text { plasma/ } \\
\text { serum }\end{array}$ & $\begin{array}{l}\text { Significantly higher in all APOE4 negative } \\
\text { subjects }(P=0.03) \text { and APOE4 negative } \\
\text { control }(P=0.016) \text { in CSF specimen. } \\
\text { Significantly higher in all control subjects than } \\
\text { AD in serum }(P=0.005) \text {. No significant } \\
\text { difference in plasma. }\end{array}$ \\
\hline $\begin{array}{l}\text { Choi et al. (2002) } \\
{[44]}\end{array}$ & $\begin{array}{l}9 \text { AD pts (age of } 70 \text { to } 89 \text { ). } 9 \text { controls (age of } \\
74 \text { to } 89 \text { ). }\end{array}$ & plasma & $\begin{array}{l}\text { Significantly higher protein carbonyl in } \mathrm{AD} \\
(P<0.05) \text {. }\end{array}$ \\
\hline $\begin{array}{l}\text { Korolainen et al. } \\
(2007)[45]\end{array}$ & $\begin{array}{l}11 \mathrm{AD} \text { pts }(\text { mean age }=73.5, \text { mild AD MMSE } \\
\text { of } 14 \text { to } 26) .8 \text { controls }(\text { mean age }=64.6)\end{array}$ & CSF & $\begin{array}{l}\text { Significantly higher carbonation of } \lambda \text { chain } \\
\text { precursor in } \operatorname{AD}(P=0.03) .\end{array}$ \\
\hline $\begin{array}{l}\text { Ahmed et al. } \\
(2005)[46]\end{array}$ & $\begin{array}{l}32 \mathrm{AD} \text { pts }(\text { mean age }=71) . \text { All before } \\
\text { treatment of AchEI. } 18 \text { controls (mean age }= \\
69) .\end{array}$ & CSF & $\begin{array}{l}\text { Significantly higher oxidized NFK and DG-H } \\
\text { in } \mathrm{AD}(P<0.05) \text {. }\end{array}$ \\
\hline $\begin{array}{l}\text { Aksenov et al. } \\
(2001)[14]\end{array}$ & $\begin{array}{l}6 \mathrm{AD} \text { pts }(\text { mean age }=80.4) .6 \text { controls } \\
(\text { mean age }=81.1)\end{array}$ & $\begin{array}{l}\text { Brain: hippocampus, } \\
\text { superior and middle } \\
\text { temporal lobe }\end{array}$ & $\begin{array}{l}\text { Significantly higher carbonated CKBB and } \\
\beta \text {-actin in } \mathrm{AD}(P<0.05) .\end{array}$ \\
\hline
\end{tabular}
Nitrated protein

$\begin{array}{llcl} & \text { 22 AD pts (mean age }=72,22 \mathrm{AD} \text { pts disease } & & \\ \text { Korolainen and } & \text { duration }=2.3 \pm 0.3, \text { MMSE }=21.3 \pm 0.9,12 & \text { CSF } / \\ \text { Pirttilä (2009) }[18] & \begin{array}{l}\text { AD pts APOE4 positive). } 10 \text { control APOE4 } \\ \text { positive. 18 controls (mean age }=68) .\end{array} & \begin{array}{l}\text { No significant difference in CSF, plasma, } \\ \text { serum }\end{array} & \text { serum. }\end{array}$


TABLE 2: Continued.

\begin{tabular}{|c|c|c|c|}
\hline Reference & Subjects' characteristic & Specimen & Results \\
\hline $\begin{array}{l}\text { Sultana et al. } \\
(2006)[43]\end{array}$ & $\begin{array}{l}6 \mathrm{AD} \text { pts }(\text { mean age }=84.5) .6 \text { controls } \\
(\text { mean age }=85.8)\end{array}$ & Brain: hippocampus & $\begin{array}{l}\text { All identified proteins with nitrated protein } \\
\text { significantly higher in } \mathrm{AD}(P \leq 0.05) \text {. }\end{array}$ \\
\hline $\begin{array}{l}\text { Tohgi et al. } \\
\text { (1999) [48] }\end{array}$ & $\begin{array}{l}25 \mathrm{AD} \text { pts (mean age }=67.9,25 \mathrm{AD} \text { pts } \\
\text { disease duration }=3.9 \pm 2.1, \mathrm{MMSE}= \\
15.6 \pm \text { 5.0. } 24 \text { controls. }\end{array}$ & CSF & $\begin{array}{l}\text { Significantly higher nitrated protein in } \mathrm{AD} \\
(P=0.0001) \text {. CSF nitrated protein inversely } \\
\text { correlated with MMSE. }\end{array}$ \\
\hline $\begin{array}{l}\text { Castegna et al. } \\
(2003)[19]\end{array}$ & $\begin{array}{l}5 \mathrm{AD} \text { pts }(\text { mean age at death }=85.5) \\
5 \text { controls (mean age at death }=83) .\end{array}$ & $\begin{array}{l}\text { Brain: inferior } \\
\text { parietal lobe }\end{array}$ & $\begin{array}{l}\text { A-Enolase, Triosephosphate isomerase, and } \\
\text { neuropolypeptide h3 nitration significantly } \\
\text { higher in AD }(P \leq 0.05)\end{array}$ \\
\hline $\begin{array}{l}\text { Hensley et al. } \\
\text { (1998) [49] }\end{array}$ & $\begin{array}{l}11 \mathrm{AD} \text { pts (mean age at death }=78.5) \text {. } \\
\text { controls (mean age at death }=78) .\end{array}$ & $\begin{array}{l}\text { Brain: hippocampus, } \\
\text { inferior parietal lobe, } \\
\text { superior and middle } \\
\text { temporal lobe, } \\
\text { cerebellum. }\end{array}$ & $\begin{array}{l}\text { Nitrated protein significantly in AD in area of } \\
\text { hippocampus, inferior parietal lobe, superior } \\
\text { and middle temporal lobe }(P<0.05) \text {. }\end{array}$ \\
\hline $\begin{array}{l}\text { Ahmed et al. } \\
\text { (2005) [46] }\end{array}$ & $\begin{array}{l}32 \mathrm{AD} \text { pts (mean age }=71 \text {, all before } \\
\text { treatment of AchEI). } 18 \text { controls (mean } \\
\text { age }=69 \text { ). }\end{array}$ & CSF & $\begin{array}{l}\text { Significantly higher nitrated protein in } \mathrm{AD} \\
(P<0.05) .\end{array}$ \\
\hline $\begin{array}{l}\text { Ryberg et al. } \\
(2004)[50]\end{array}$ & $\begin{array}{l}17 \text { AD pts (mean age }=73.4 \text {, mild AD pts } \\
\text { MMSE of } 19 \text { to } 24 \text {, moderate AD pts MMSE } \\
\text { of } 12 \text { to } 18 \text {, severe AD pts MMSE of } 0 \text { to } 12 . \\
19 \text { controls (mean age }=68 \text { ). }\end{array}$ & CSF & $\begin{array}{l}\text { No difference of nitrated protein between } \mathrm{AD} \\
\text { and control. }\end{array}$ \\
\hline
\end{tabular}

3.3.5. Superoxide Dismutase (SOD). As an antioxidant enzyme, SOD may be induced or consumed by oxidative stress [65]. It is one of the most studied antioxidant enzymes in AD. Several studies find no difference in SOD between $\mathrm{AD}$ and controls $[15,29,31,36,66]$. Some find significantly lower erythrocyte level $[5,11,54,67]$ and plasma/serum level $[11,26]$ in $\mathrm{AD}$, while others find significantly higher erythrocyte $[6,7,21,22,68-71]$ and plasma [28] levels in AD. However, only three among these studies have a case number more than $80[7,22,68]$ and all of them either include only mild-to-moderate $\mathrm{AD}[22,68]$ or have clear severity-classification of $\mathrm{AD}$ [7]. All three demonstrate significantly higher erythrocyte SOD level in AD [7, 21, 22]. One study further establishes that leukocyte SOD level is higher in moderate $\mathrm{AD}$ than in mild $\mathrm{AD}$, higher in mild $\mathrm{AD}$ than in controls, and higher in mild $\mathrm{AD}$ than in severe $\mathrm{AD}$ [7]. This suggests that SOD level is induced by oxidative stress in the early stages of $\mathrm{AD}$ and is consumed in the later stage. Studies with different findings may be due to limitations of small sample size $[26,66]$ or loose inclusion criteria $[15,21,29,36,54]$.

\subsubsection{Glutathione Peroxidase (GPx)/Reduced Glutathione} (GSH). Glutathione peroxidase, another antioxidant enzyme, may be also induced or consumed under conditions of oxidative stress [65]. Some studies demonstrate no difference in GPx level between $\mathrm{AD}$ and controls $[15,22,29,31]$. Some demonstrate lower GPx in AD [26$28,36,54]$, while others observe higher GPx [5, 7, 24, 27]. As for the balance between reduced and oxidized GSH (GSSG), some studies show no significant difference between $\mathrm{AD}$ and controls $[6,20,29]$, while others demonstrate a balance towards GSSG in AD with statistical significance $[7,32,41,72,73]$. The only study with a case number more than 100 demonstrates significantly higher plasma, erythrocyte, and leukocyte GPx and GSSG levels in severe $\mathrm{AD}$ than in moderate $\mathrm{AD}$, in moderate $\mathrm{AD}$ than in mild $\mathrm{AD}$, and in mild $\mathrm{AD}$ than in controls [7]. Other studies may be limited by their small sample size $[6,15,26]$ or different patient characteristics $[20,31,54]$.

3.4. Biomarkers of DNA Oxidation . $8-\mathrm{OHdG}$ is the most commonly studied biomarker for oxidative DNA. Most studies in the literature reveal significantly higher 8 -OHdG in $\mathrm{AD}[4,16,74]$. Among the three, two studies demonstrated significantly higher peripheral 8-OHdG in lymphocytes and leukocytes $[4,16]$.

3.5. Biomarkers of Central Nervous System. As for CSF antioxidant, the difference of vitamin E level between $\mathrm{AD}$ and controls remains controversial $[58,64]$. Although one study shows no difference in CSF vitamin C level between AD and controls [75], two other studies reveal that CSF vitamin $\mathrm{C}$ level is lower $[60,64]$ and one study even has negative findings, which may be due to the small sample size [75]. Only one study about CSF vitamin A level shows no difference between $\mathrm{AD}$ and control [64].

In terms of markers of oxidative stress measured closer to the brain, one of the studies that measured brain 8OHdG directly found elevated $8-\mathrm{OHdG}$ in $\mathrm{AD}$ [74]. CSF protein carbonyl level is universally significantly higher in $\mathrm{AD}$ than in controls $[18,45,46]$. Furthermore, several studies measure protein carbonyls directly in the brain postmortem $[14,43$, 47]. Although most studies on the hippocampus have found exclusively significantly higher protein carbonyl levels in $\mathrm{AD}$, one study on other brain regions such as the neocortex, amygdala, brainstem, and cerebellum has also 
TABLE 3: Studies exploring the predictive capacity of antioxidant in AD.

\begin{tabular}{|c|c|c|c|}
\hline Reference & Subjects' characteristic & Specimen & Results \\
\hline \multicolumn{4}{|c|}{ Antioxidant-uric acid } \\
\hline $\begin{array}{l}\text { Polidori et al. } \\
(2002)[25]\end{array}$ & $\begin{array}{l}35 \mathrm{AD} \text { pts }(\text { mean age }=85.9) .40 \text { controls } \\
(\text { mean age }=85.5) .\end{array}$ & Plasma & $\begin{array}{l}\text { No significant difference between } \mathrm{AD} \text { and } \\
\text { controls. }\end{array}$ \\
\hline $\begin{array}{l}\text { Carantoni et al. } \\
(2000)[8]\end{array}$ & $\begin{array}{l}24 \mathrm{AD} \text { pts (mean age }=83) \text {. Exclusion criteria: } \\
\mathrm{DM} \text {, taking any drug that influences blood } \\
\text { glucose and lipid. } 66 \text { controls (mean age }=85) \text {. }\end{array}$ & Plasma & $\begin{array}{l}\text { No significant difference between } \mathrm{AD} \text { and } \\
\text { controls }\end{array}$ \\
\hline $\begin{array}{l}\text { Kim et al. (2006) } \\
{[52]}\end{array}$ & $\begin{array}{l}101 \mathrm{AD} \text { pts (mean age }=73.5 \text { ). Exclusion } \\
\text { criteria: DM, hypertension, hyperlipidemia. } \\
\text { AD MMSE } 17 \pm 5.8 .101 \text { controls (mean age }= \\
73.2 \text { ). }\end{array}$ & Plasma & Significantly lower in $\mathrm{AD}(P<0.0001)$. \\
\hline $\begin{array}{l}\text { Maesaka et al. } \\
(1993)[53]\end{array}$ & 18 AD pts. 11 controls. & Serum & Significantly lower in $\mathrm{AD}(P<0.02)$ \\
\hline $\begin{array}{l}\text { Rinaldi et al. } \\
(2003)[54]\end{array}$ & $\begin{array}{l}63 \mathrm{AD} \text { pts (mean age }=76.8) . \text { Exclusion } \\
\text { criteria: smoking, alcohol abuse, major organ } \\
\text { failure, dyslipidemia, and malnutrition. } 56 \\
\text { controls (mean age }=75.8 \text { ). }\end{array}$ & Plasma & Significantly lower in $\mathrm{AD}(P<0.001)$ \\
\hline \multicolumn{4}{|c|}{ Antioxidant-vitamin E } \\
\hline $\begin{array}{l}\text { Bourdel- } \\
\text { Marchasson } \\
\text { et al. (2001) [15] }\end{array}$ & $\begin{array}{l}20 \mathrm{AD} \text { pts (mean age }=80.1 \text { ). Follow-up at } \\
\text { memory center for more than } 6 \text { months, no } \\
\text { evidence of nutritional behavior, mean } \\
\text { duration of } \mathrm{AD}=3.9 \text { years, } 19 \text { pts on } \\
\text { cholinergic therapy. } 23 \text { controls (mean age = } \\
76.0 \text { ). }\end{array}$ & $\begin{array}{l}\text { Plasma/ } \\
\text { erythrocytes }\end{array}$ & $\begin{array}{l}\text { Significant plasma level in } \mathrm{AD}(P=0.002) \text {. No } \\
\text { difference in erythrocytes level. }\end{array}$ \\
\hline $\begin{array}{l}\text { Cristalli et al. } \\
\text { (2012) [7] }\end{array}$ & $\begin{array}{l}110 \text { AD pts (mean age }=74.7 \text {, GDS } 3=\text { mild, } \\
\text { GDS } 4-5=\text { intermediate, GDS } 6-7=\text { severe) } \\
\text { No further exclusion criteria. } 134 \text { controls } \\
\text { (mean age }=77.8)\end{array}$ & Plasma & $\begin{array}{l}\text { Significantly lower in mild AD in comparison } \\
\text { with control, lower in intermediate } \mathrm{AD} \text { in } \\
\text { comparison with mild } \mathrm{AD} \text {, and lower in severe } \\
\mathrm{AD} \text { in comparison with intermediate } \mathrm{AD} \text {. }\end{array}$ \\
\hline $\begin{array}{l}\text { Polidori et al. } \\
(2002)[25]\end{array}$ & $\begin{array}{l}35 \mathrm{AD} \text { pts }(\text { mean age }=85.9) .40 \text { controls } \\
(\text { mean age }=85.5) .\end{array}$ & Plasma & $\begin{array}{l}\text { Significantly lower in } \mathrm{AD} \text { in plasma level } \\
(P<0.001) .\end{array}$ \\
\hline $\begin{array}{l}\text { Jiménez-Jiménez } \\
\text { et al. (1997) [58] }\end{array}$ & $44 \mathrm{AD}$ pts. 37 controls. & $\begin{array}{c}\text { Serum/ } \\
\text { CSF/ } \\
\text { serum-CSF ratio }\end{array}$ & $\begin{array}{l}\text { Significantly lower in serum and CSF in AD } \\
\text { but no difference in serum-CSF ratio. }\end{array}$ \\
\hline $\begin{array}{l}\text { Riviere et al. } \\
(1998)[62]\end{array}$ & $\begin{array}{l}44 \mathrm{AD} \text { pts (mean age }=78.5, \mathrm{MMSE}<24) .20 \\
\text { controls (mean age }=79.3 \text { ). }\end{array}$ & Plasma & $\begin{array}{l}\text { No significant difference between } \mathrm{AD} \text { and } \\
\text { control. }\end{array}$ \\
\hline $\begin{array}{l}\text { Rinaldi et al. } \\
\text { (2003) [54] }\end{array}$ & $\begin{array}{l}63 \mathrm{AD} \text { pts (mean age }=76.8 \text { ). Exclusion } \\
\text { criteria: smoking, alcohol abuse, major organ } \\
\text { failure, dyslipidemia, and malnutrition. } 56 \\
\text { controls (mean age }=75.8 \text { ). }\end{array}$ & Plasma & Significantly lower in $\mathrm{AD}(P<0.0001)$ \\
\hline $\begin{array}{l}\text { Iuliano et al. } \\
(2010) \text { [57] }\end{array}$ & $\begin{array}{l}37 \mathrm{AD} \text { pts (vitamin E levels corrected for } \\
\text { cholesterol). } 24 \text { controls. }\end{array}$ & Plasma & Reduced in AD patients $(P<0.05)$. \\
\hline $\begin{array}{l}\text { Schippling et al. } \\
(2000)[64]\end{array}$ & $\begin{array}{l}26 \mathrm{AD} \text { pts }(\text { mean age }=73.9) .14 \text { controls }(\text { mean } \\
\text { age }=70.3) .\end{array}$ & $\mathrm{CSF} /$ plasma & No significant difference in CSF and plasma. \\
\hline $\begin{array}{l}\text { Glasø et al. } \\
(2004)[60]\end{array}$ & 20 AD pts. 18 controls. & Serum & Significantly lower in $\mathrm{AD}(P<0.05)$. \\
\hline $\begin{array}{l}\text { Sinclair et al. } \\
(1998)[9]\end{array}$ & $\begin{array}{l}25 \mathrm{AD} \text { pts }(\text { mean age }=74.3, \text { median } \mathrm{MMSE}= \\
19) .41 \text { controls }(\text { mean age }=73.4) .\end{array}$ & Plasma & Significantly lower in $\mathrm{AD}(P=0.035)$. \\
\hline $\begin{array}{l}\text { Foy et al. (1999) } \\
{[10]}\end{array}$ & $\begin{array}{l}79 \mathrm{AD} \text { pts (median age }=79, \mathrm{MMSE} \text { of } 10 \text { to } \\
\text { 25). } 58 \text { controls (median age }=74 \text { ). }\end{array}$ & Plasma & Significantly lower in $\mathrm{AD}(P<0.01)$. \\
\hline $\begin{array}{l}\text { von Arnim et al. } \\
(2012)[63]\end{array}$ & 74 AD pts. 158 controls. & Serum & $\begin{array}{l}\text { No difference between mild dementia and } \\
\text { control. }\end{array}$ \\
\hline $\begin{array}{l}\text { Mecocci et al. } \\
(2002)[16]\end{array}$ & $\begin{array}{l}40 \mathrm{AD} \text { pts }(\text { mean age }=75.9, \text { mean } \mathrm{MMSE}= \\
17.3) .39 \text { controls }(\text { mean age }=74.8) .\end{array}$ & Plasma & Significantly lower in $\operatorname{AD}(P<0.001)$. \\
\hline
\end{tabular}


TABLe 3: Continued.

\begin{tabular}{|c|c|c|c|}
\hline Reference & Subjects' characteristic & Specimen & Results \\
\hline \multicolumn{4}{|c|}{ Antioxidant-vitamin C } \\
\hline $\begin{array}{l}\text { Polidori et al. } \\
(2002)[25]\end{array}$ & $\begin{array}{l}35 \mathrm{AD} \text { pts }(\text { mean age }=85.9) .40 \text { controls } \\
(\text { mean age }=85.5) .\end{array}$ & plasma & $\begin{array}{l}\text { Significantly lower in } \mathrm{AD} \text { in plasma level } \\
(P<0.001) \text {. }\end{array}$ \\
\hline $\begin{array}{l}\text { Riviere et al. } \\
(1998)[62]\end{array}$ & $44 \mathrm{AD}$ pts (mean age = 78.5) & Plasma & $\begin{array}{l}\text { Significantly lower in moderate and severe AD } \\
(P<0.005)\end{array}$ \\
\hline $\begin{array}{l}\text { von Arnim et al. } \\
\text { (2012) [63] }\end{array}$ & 74 AD pts. 158 controls & Serum & $\begin{array}{l}\text { Significantly lower in demented subjects after } \\
\text { adjusting for school education, intake of } \\
\text { dietary supplements, smoking habit, body mass } \\
\text { index, and alcohol consumption. }\end{array}$ \\
\hline $\begin{array}{l}\text { Rinaldi et al. } \\
(2003)[54]\end{array}$ & $\begin{array}{l}63 \mathrm{AD} \text { pts (mean age }=76.8 \text { ). Exclusion } \\
\text { criteria: smoking, alcohol abuse, major organ } \\
\text { failure, dyslipidemia, and malnutrition. } 56 \\
\text { controls (mean age }=75.8 \text { ). }\end{array}$ & Plasma & Significantly lower in $\operatorname{AD}(P<0.0001)$ \\
\hline $\begin{array}{l}\text { Glaso et al. } \\
(2004)[60]\end{array}$ & 20 AD pts. 18 controls. & Serum/CSF & Significantly lower in $\mathrm{AD}(P<0.05)$. \\
\hline $\begin{array}{l}\text { Sinclair et al. } \\
(1998)[9]\end{array}$ & $\begin{array}{l}25 \mathrm{AD} \text { pts }(\text { mean age }=74.3, \mathrm{AD} \text { median } \\
\mathrm{MMSE}=19) .41 \text { controls }(\text { mean age }=73.4) .\end{array}$ & Plasma & $\begin{array}{l}\text { No significant difference between } \mathrm{AD} \text { and } \\
\text { control. }\end{array}$ \\
\hline $\begin{array}{l}\text { Foy et al. (1999) } \\
{[10]}\end{array}$ & $\begin{array}{l}79 \mathrm{AD} \text { pts (median age }=79, \mathrm{MMSE} \text { of } 10 \text { to } \\
\text { 25). } 58 \text { controls (median age }=74 \text { ). }\end{array}$ & Plasma & Significantly lower in $\mathrm{AD}(P<0.001)$. \\
\hline $\begin{array}{l}\text { Paraskevas et al. } \\
\text { (1997) [75] }\end{array}$ & 17 AD pts. 15 controls. & Plasma/CSF & No significant difference. \\
\hline $\begin{array}{l}\text { Schippling et al. } \\
(2000) \text { [64] }\end{array}$ & $\begin{array}{l}26 \mathrm{AD} \text { pts }(\text { mean age }=73.9) .14 \text { controls }(\text { mean } \\
\text { age }=70.3) .\end{array}$ & CSF/plasma & $\begin{array}{l}\text { No significant difference in plasma, but } \\
\text { significantly lower in CSF }(P<0.01) \text {. }\end{array}$ \\
\hline $\begin{array}{l}\text { Mecocci et al. } \\
(2002)[16]\end{array}$ & $\begin{array}{l}40 \mathrm{AD} \text { pts }(\text { mean age }=75.9, \text { mean } \mathrm{MMSE}= \\
17.3) .39 \text { controls }(\text { mean age }=74.8) .\end{array}$ & Plasma/ & Significantly lower in $\mathrm{AD}(P<0.001)$. \\
\hline
\end{tabular}

Antioxidant-vitamin A/carotene

Polidori et al. $\quad 35 \mathrm{AD}$ pts (mean age $=85.9) .40$ controls (2002) $[25] \quad$ (mean age $=85.5$ )

plasma Significantly lower in $\mathrm{AD}$ in plasma level $(P<0.001)$.

von Arnim et al. (2012) [63]

$74 \mathrm{AD}$ pts. 158 controls.
Significantly lower in demented subjects after adjusting for school education, intake of dietary supplements, smoking habit, body mass index, and alcohol consumption.

$63 \mathrm{AD}$ pts (mean age $=76.8$ ). Exclusion

$\begin{array}{lll}\text { Rinaldi et al. } & \text { criteria: smoking, alcohol abuse, major organ } & \text { Plasma }\end{array} \quad$ Significantly lower in AD $(P<0.001)$ controls (mean age $=75.8$ ).

Schippling et al. $26 \mathrm{AD}$ pts (mean age $=73.9)$. 14 controls (mean (2000) [64] age $=70.3)$.

Sinclair et al. $\quad 25 \mathrm{AD}$ pts (mean age $=74.3$, median MMSE $=$ (1998) [9] 19). 41 controls (mean age $=73.4$ ).

Serum

Foy et al. (1999) 79 AD pts (median age $=79$, MMSE of 10 to

[10] 25). 58 controls (median age $=74$ ).

No significant difference in CSF but significantly lower in plasma $(P<0.001)$.

Mecocci et al $40 \mathrm{AD}$ pts (mean age $=75.9$, mean MMSE $=$ (2002) $[16] \quad 17.3) .39$ controls (mean age $=74.8)$

\section{Antioxidant-SOD}

$50 \mathrm{AD}$ pts (22 pts aged from 65 to 74,23 pts aged from 75 to 84 , five pts aged $>85$ ).

Casado et al. Exclusion criteria: DM, myeloproliferative (2008) [5] disorders, uncontrolled hypertension, mental retardation, and malnutrition. 50 controls (24 subjects aged from 65 to 74,21 subjects aged

Erythrocytes (HPLC)
Significantly lower in $\mathrm{AD}$ within group aged 65-74 years $(P<0.02)$, group aged $75-84$ years $(P<0.005)$, and group aged $85-94$ years $(P<0.001)$. 
TABLE 3: Continued.

\begin{tabular}{llll}
\hline Reference & Subjects' characteristic & Specimen & Results \\
\hline $\begin{array}{l}\text { Jeandel et al. } \\
(1989)[36]\end{array}$ & 55 AD pts. 24 controls. & Erythrocytes & $\begin{array}{l}\text { No significant difference between AD and } \\
\text { controls. }\end{array}$ \\
\hline $\begin{array}{l}\text { Ceballos-Picot } \\
\text { et al. (1996) [31] }\end{array}$ & $\begin{array}{l}\text { 40 AD pts (mean age }=84.2) \text {. Exclusion } \\
\text { criteria: life expectancy less than 4 months, } \\
\text { taking steroids, and blindness or deafness. 34 } \\
\text { controls (mean age }=79.1) .\end{array}$ & Erythrocytes & $\begin{array}{l}\text { No significant difference between AD and } \\
\text { controls. }\end{array}$ \\
\hline
\end{tabular}

27 AD pts (mean age $=72.3$ ). Exclusion

Ozcankaya and criteria: life expectancy less than 3 months,

Delibas (2002) taking steroids, blindness and deafness, iron for

[21] anemia, illiterate patients, and medical

disorder other than dementia. 25 controls

(mean age $=64.4$ ).

112 AD pts (mean age $=72.1$ ). Exclusion

criteria: head trauma, seizures, uncontrolled

Serra et al. hypertension, mental retardation, psychosis or

(2009) [22]

depression, smoking within 5 years, and

Erythrocytes Significantly higher in $\operatorname{AD}(P<0.001)$.

vascular insult. Inclusion criteria: GDS of 3 to

5.80 controls (mean age $=68.4$ ).

Erythrocytes Significantly higher in $\operatorname{AD}(P<0.001)$.

$\begin{array}{ll} & 5.80 \text { controls (mean age }=68.4) . \\ & \\ \text { Cristalli et al. } & \begin{array}{l}\text { GDS } 4-5=\text { intermediate, GDS } 6-7=\text { severe) } \\ \text { (2012) [7] }\end{array} \\ \begin{array}{l}\text { No further exclusion criteria. } 134 \text { controls } \\ \text { (mean age }=77.8) .\end{array}\end{array}$

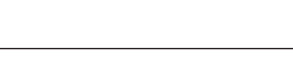

Significantly higher in mild, intermediate, and severe $\mathrm{AD}$ in comparison with control in erythrocytes and leukocytes samples.

Cristalli et al. GDS 4-5 = intermediate, GDS 6-7 = severe). (mean age $=77.8$ ).

Erythrocyte/ leukocytes
Significantly higher in severe AD than intermediate $\mathrm{AD}$, higher in intermediate $\mathrm{AD}$ than mild $\mathrm{AD}$ in erythrocyte sample $(P<0.05)$. Significantly higher in intermediate $\mathrm{AD}$ than mild $\mathrm{AD}$, higher in mild $\mathrm{AD}$ than severe AD in leukocyte sample $(P<0.05)$.

\begin{tabular}{|c|c|c|c|}
\hline & & & \\
\hline $\begin{array}{l}\text { Bourdel- } \\
\text { Marchasson } \\
\text { et al. (2001) [15] }\end{array}$ & $\begin{array}{l}20 \mathrm{AD} \text { pts (mean age }=80.1 \text { ). Follow-up at } \\
\text { memory center for more than } 6 \text { months, no } \\
\text { evidence of nutritional behavior, mean } \\
\text { duration of } \mathrm{AD}=3.9 \text { years, } 19 \text { pts on } \\
\text { cholinergic therapy. } 23 \text { controls (mean age = } \\
76.0 \text { ). }\end{array}$ & Erythrocytes & $\begin{array}{l}\text { No significant difference between } \mathrm{AD} \text { and } \\
\text { controls. }\end{array}$ \\
\hline $\begin{array}{l}\text { Serra et al. } \\
\text { (2001) [6] }\end{array}$ & $18 \mathrm{AD}$ pts. 14 controls. & Erythrocytes & Significantly higher in $\mathrm{AD}(P=0.0000001)$. \\
\hline $\begin{array}{l}\text { Padurariu et al. } \\
\text { (2010) [26] }\end{array}$ & $\begin{array}{l}15 \mathrm{AD} \text { pts (mean age }=65.8, \mathrm{MMSE}= \\
18.5 \pm 0.3, \mathrm{ADAS}-\mathrm{cog}=18.5 \pm 0.3, \text { not taking } \\
\text { antioxidant supplement). } 15 \text { controls (mean } \\
\text { age }=62.5 \text { ) }\end{array}$ & Serum & $\begin{array}{l}\text { Significantly lower in } \mathrm{AD} \text { in serum level } \\
(P<0.0004) .\end{array}$ \\
\hline $\begin{array}{l}\text { Puertas et al. } \\
(2012)[28]\end{array}$ & $\begin{array}{l}20 \mathrm{AD} \text { men }(\text { mean age }=70.6, \text { MMSE } \\
23.7 \pm 0.92) .26 \mathrm{AD} \text { women (mean age }=73.9 \text {, } \\
\text { MMSE } 20.7 \pm 0.66 \text { ). Exclusion criteria: taking } \\
\text { NSAIDs, steroids, vitamins or antioxidant } \\
\text { supplements, history of smoking and alcohol } \\
\text { intake, and comorbidity with other clinical } \\
\text { major neurological illnesses. } 16 \text { control men } \\
\text { (mean age }=73.3) .30 \text { control women (mean } \\
\text { age }=73.8) .\end{array}$ & Plasma & $\begin{array}{l}\text { Significantly higher in total AD in plasma level } \\
(P<0.01) \text {, but not in men and women } \\
\text { separately. }\end{array}$ \\
\hline $\begin{array}{l}\text { Rinaldi et al. } \\
(2003)[54]\end{array}$ & $\begin{array}{l}63 \mathrm{AD} \text { pts (mean age }=76.8 \text { ). Exclusion } \\
\text { criteria: smoking, alcohol abuse, major organ } \\
\text { failure, dyslipidemia, and malnutrition. } 56 \\
\text { controls (mean age }=75.8 \text { ) }\end{array}$ & Erythrocytes & Significantly lower in $\mathrm{AD}(P<0.0001)$. \\
\hline $\begin{array}{l}\text { Ihara et al. } \\
\text { (1997) [11] }\end{array}$ & $\begin{array}{l}22 \mathrm{AD} \text { pts }(\text { mean age }=74.8) .19 \text { controls (mean } \\
\text { age }=73.5) .\end{array}$ & $\begin{array}{l}\text { Erythrocytes/ } \\
\text { plasma }\end{array}$ & Significantly lower in $\mathrm{AD}(P<0.001)$ \\
\hline $\begin{array}{l}\text { Kharrazi et al. } \\
(2008)[68]\end{array}$ & $\begin{array}{l}91 \mathrm{AD} \text { pts }(\text { mean age }=75, \mathrm{MMSE}=18.4 \pm 4.8) . \\
91 \text { controls }(\text { mean age }=73.5)\end{array}$ & Erythrocytes & Significantly higher in $\mathrm{AD}(P=0.001)$. \\
\hline $\begin{array}{l}\text { Perrin et al. } \\
\text { (1990) [69] }\end{array}$ & $25 \mathrm{AD}$ pts. 25 controls. & Erythrocytes & Significantly higher in $\mathrm{AD}(P<0.05)$. \\
\hline
\end{tabular}


TABLE 3: Continued.

\begin{tabular}{|c|c|c|c|}
\hline Reference & Subjects' characteristic & Specimen & Results \\
\hline $\begin{array}{l}\text { Rossi et al. } \\
(2002)[70]\end{array}$ & $\begin{array}{l}32 \mathrm{AD} \text { pts (mean age }=72, \mathrm{MMSE}=19.2 \pm 5.8) \\
22 \text { controls }(\text { mean age }=70)\end{array}$ & Erythrocytes & Significantly higher in $\mathrm{AD}(P=0.014)$. \\
\hline $\begin{array}{l}\text { Snaedal et al. } \\
\text { (1998) [67] }\end{array}$ & 44 AD pts. 44 controls. & Erythrocytes & Significantly lower in $\operatorname{AD}(P=0.019)$. \\
\hline $\begin{array}{l}\text { Tabet et al. } \\
(2001)[66]\end{array}$ & $\begin{array}{l}7 \text { AD pts (mean age }=75 \text {, MMSE } 21 \pm 1.6 \text { ). } \\
\text { Exclusion criteria: other physical } \\
\text { illnesses/treatments that could influence free } \\
\text { radical or antioxidant levels (e.g., cancer, } \\
\text { radiation therapy, oxygen intoxication, or liver } \\
\text { disease). } 6 \text { controls (mean age }=71 \text { ). }\end{array}$ & Erythrocytes & No significant difference. \\
\hline $\begin{array}{l}\text { De Leo et al. } \\
\text { (1998) [71] }\end{array}$ & $\begin{array}{l}31 \mathrm{AD} \text { pts (mean age at 65.4, MMSE >16). } 21 \\
\text { controls (mean age }=66.2 \text { ). }\end{array}$ & Erythrocytes & Significantly higher in $\mathrm{AD}(P<0.01)$. \\
\hline
\end{tabular}

Glutathione peroxidase/glutathione reductase/reduced glutathione

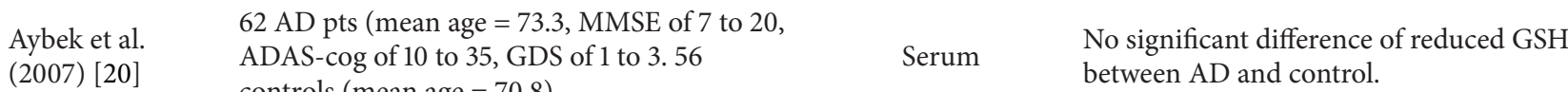

\begin{tabular}{|c|c|c|c|}
\hline $\begin{array}{l}\text { Casado et al. } \\
(2008)[5]\end{array}$ & $\begin{array}{l}50 \mathrm{AD} \text { pts ( } 22 \text { pts aged from } 65 \text { to } 74,23 \text { pts } \\
\text { aged from } 75 \text { to } 84 \text {, five pts aged }>85 \text { ). } \\
\text { Exclusion criteria: DM, myeloproliferative } \\
\text { disorders, uncontrolled hypertension, mental } \\
\text { retardation, and malnutrition. } 50 \text { controls ( } 24 \\
\text { subjects aged from } 65 \text { to } 74,21 \text { subjects aged } \\
\text { from } 75 \text { to } 84 \text {, five subjects aged }>85 \text {. }\end{array}$ & $\begin{array}{l}\text { Erythrocytes } \\
\text { (HPLC) }\end{array}$ & $\begin{array}{l}\text { Significantly higher glutathione peroxidase } \\
(\mathrm{GPX}) \text { in AD within group aged } 65-74 \text { years } \\
(P<0.005) \text { and group aged } 75-84 \text { years } \\
(P<0.005) \text {, but not within group aged } 85-94 \\
\text { years. }\end{array}$ \\
\hline $\begin{array}{l}\text { Ceballos-Picot } \\
\text { et al. (1996) [31] }\end{array}$ & $\begin{array}{l}40 \mathrm{AD} \text { pts (mean age }=84.2 \text { ). Exclusion } \\
\text { criteria: life expectancy less than } 4 \text { months, } \\
\text { taking steroids, and blindness or deafness. } 34 \\
\text { controls (mean age }=79.1 \text { ). }\end{array}$ & Plasma & $\begin{array}{l}\text { No significant difference of GPX between AD } \\
\text { and controls. }\end{array}$ \\
\hline $\begin{array}{l}\text { Jeandel et al. } \\
(1989)[36]\end{array}$ & 55 AD pts. 24 controls. & Erythrocytes & Significantly lower of GPX in AD $(P<0.05)$. \\
\hline $\begin{array}{l}\text { Gironi et al. } \\
\text { (2011) [32] }\end{array}$ & $\begin{array}{l}25 \mathrm{AD} \text { pts (mean age }=78.2 \text { ). Inclusion age of } \\
65 \text { to } 90 . \text { Exclusion criteria: vascular insult, } \\
\text { DM, chronic infection, malignant disease, } \\
\text { severe renal, hepatic cardiorespiratory or } \\
\text { hematological disease, and use of vitamin } \\
\text { supplementation. } 66 \text { controls (mean age = } \\
70.4 \text { ). }\end{array}$ & Serum & $\begin{array}{l}\text { Significantly lower in reduced GSH in AD } \\
(P<0.05) .\end{array}$ \\
\hline
\end{tabular}

112 AD pts (mean age $=72.1)$. Exclusion criteria: head trauma, seizures, uncontrolled

Serra et al. hypertension, mental retardation, psychosis or (2009) [22] depression, smoking within 5 years, and Plasma No significant difference of GPX. vascular insult. Inclusion criteria: GDS of 3 to 5. 80 controls (mean age $=68.4$ ).

\begin{tabular}{|c|c|c|c|}
\hline $\begin{array}{l}\text { Torres et al. } \\
\text { (2011) [24] }\end{array}$ & 29 AD pts. 26 controls & Serum & Significantly higher GPX in AD $(P<0.05)$. \\
\hline $\begin{array}{l}\text { Cristalli et al. } \\
(2012) \text { [7] }\end{array}$ & $\begin{array}{l}110 \text { AD pts (mean age }=74.7 \text {, GDS } 3=\text { mild, } \\
\text { GDS } 4-5=\text { intermediate, GDS } 6-7=\text { severe). } \\
\text { No further exclusion criteria. } 134 \text { controls } \\
(\text { mean age }=77.8) .\end{array}$ & $\begin{array}{l}\text { Plasma/ } \\
\text { erythrocyte/ } \\
\text { leukocytes }\end{array}$ & $\begin{array}{l}\text { Significantly higher oxidized GSH (GSSG) in } \\
\text { severe AD than intermediate AD, intermediate } \\
\text { AD than mild AD, and mild AD than control. } \\
\text { Significantly lower GSH/GSSG in similar } \\
\text { pattern. All of these findings present plasma, } \\
\text { erythrocytes. Significantly higher GPX in } \\
\text { severe AD than intermediate AD, intermediate } \\
\text { AD than mild AD, and mild AD than control. }\end{array}$ \\
\hline
\end{tabular}


TABLE 3: Continued.

\begin{tabular}{|c|c|c|c|}
\hline Reference & Subjects' characteristic & Specimen & Results \\
\hline $\begin{array}{l}\text { Bourdel- } \\
\text { Marchasson } \\
\text { et al. (2001) [15] }\end{array}$ & $\begin{array}{l}20 \mathrm{AD} \text { pts (mean age }=80.1 \text { ). Follow-up at } \\
\text { memory center for more than } 6 \text { months, no } \\
\text { evidence of nutritional behavior, mean } \\
\text { duration of } \mathrm{AD}=3.9 \text { years, } 19 \text { pts on } \\
\text { cholinergic therapy. } 23 \text { controls (mean age }= \\
76.0 \text { ) }\end{array}$ & $\begin{array}{l}\text { Plasma/ } \\
\text { erythrocytes }\end{array}$ & $\begin{array}{l}\text { No significant difference of GPX between AD } \\
\text { and control in erythrocytes level. }\end{array}$ \\
\hline $\begin{array}{l}\text { Serra et al. } \\
(2001)[6]\end{array}$ & 18 AD pts. 14 controls. & Erythrocytes & $\begin{array}{l}\text { No significant difference of GSH between AD } \\
\text { and controls. }\end{array}$ \\
\hline $\begin{array}{l}\text { Padurariu et al. } \\
\text { (2010) [26] }\end{array}$ & $\begin{array}{l}15 \mathrm{AD} \text { pts (mean age }=65.8, \mathrm{MMSE}= \\
18.5 \pm 0.3 \text {, ADAS-cog }=18.5 \pm 0.3 \text {, not taking } \\
\text { antioxidant supplement). } 15 \text { controls (mean } \\
\text { age }=62.5)\end{array}$ & Serum & $\begin{array}{l}\text { Significantly lower GPX in AD in serum level } \\
(P<0.0001) \text {. }\end{array}$ \\
\hline $\begin{array}{l}\text { Puertas et al. } \\
(2012)[28]\end{array}$ & $\begin{array}{l}20 \mathrm{AD} \text { men }(\text { mean age }=70.6, \mathrm{MMSE}= \\
23.7 \pm 0.92) .26 \mathrm{AD} \text { women }(\text { mean age }=73.9, \\
\text { MMSE }=20.7 \pm 0.66) . \text { Exclusion criteria: taking } \\
\text { NSAIDs, steroids, vitamins or antioxidant } \\
\text { supplements, history of smoking and alcohol } \\
\text { intake, and comorbidity with other clinical } \\
\text { major neurological illnesses. } 16 \text { control men } \\
(\text { mean age }=73.3) .30 \text { control women (mean } \\
\text { age }=73.8) .\end{array}$ & Plasma & $\begin{array}{l}\text { Significantly lower GPX in both male and } \\
\text { female AD in plasma level }(P<0.01) \text {. }\end{array}$ \\
\hline $\begin{array}{l}\text { Bermejo et al. } \\
(2008)[41]\end{array}$ & 45 AD pts. 28 controls. & Serum & $\begin{array}{l}\text { Significantly lower GSH/GSSG in AD } \\
(P<0.05) .\end{array}$ \\
\hline $\begin{array}{l}\text { Rinaldi et al. } \\
(2003)[54]\end{array}$ & $\begin{array}{l}63 \mathrm{AD} \text { pts (mean age }=76.8 \text { ). Exclusion } \\
\text { criteria: smoking, alcohol abuse, major organ } \\
\text { failure, dyslipidemia, and malnutrition. } 56 \\
\text { controls (mean age }=75.8 \text { ). }\end{array}$ & Plasma & Significantly lower GPX in AD $(P<0.0001)$. \\
\hline $\begin{array}{l}\text { Baldeiras et al. } \\
(2008)[73]\end{array}$ & $42 \mathrm{AD}$ pts. 37 controls. & Plasma & Significantly higher GSSG in AD $(P<0.05)$. \\
\hline $\begin{array}{l}\text { Vural et al. } \\
\text { (2010) [76] }\end{array}$ & $\begin{array}{l}50 \mathrm{AD} \text { pts (mean age }=71.9) \text {. Exclusion criteria: } \\
\text { drug abuse, DM, hypertension, severe head } \\
\text { injury, and seizure disorder. } 50 \text { controls (mean } \\
\text { age }=65.1) \text {. }\end{array}$ & Plasma & Significantly lower GPX in AD $(P<0.01)$. \\
\hline \multicolumn{4}{|c|}{ 8-hydroxyguanosine } \\
\hline $\begin{array}{l}\text { Mecocci et al. } \\
(2002)[16]\end{array}$ & $\begin{array}{l}40 \mathrm{AD} \text { pts }(\text { mean age }=75.9, \mathrm{MMSE}= \\
17.3 \pm 2.1) .39 \text { controls }(\text { mean age }=74.8)\end{array}$ & Lymphocytes & Significantly higher in $\mathrm{AD}(P<0.001)$ \\
\hline $\begin{array}{l}\text { Migliore et al. } \\
(2005)[4]\end{array}$ & $\begin{array}{l}20 \mathrm{AD} \text { pts }(\text { mean age }=71.05, \mathrm{AD} \text { disease } \\
\text { duration }=3.3 \pm 1.53) .15 \text { controls (mean age }= \\
65.8)\end{array}$ & Leukocytes & Significantly higher in $\mathrm{AD}(P<0.001)$. \\
\hline $\begin{array}{l}\text { Nunomura et al. } \\
\text { (2012) [74] }\end{array}$ & $\begin{array}{l}15 \mathrm{AD} \text { pts (mean age }=89.5) \text {. Pathologically } \\
\text { definite AD classified into preclinical, MCI, } \\
\text { and mild AD. } 5 \text { controls (mean age }=88.4)\end{array}$ & Brain & $\begin{array}{l}\text { Significantly higher in mild AD and MCI than } \\
\text { preclinical and control. }\end{array}$ \\
\hline
\end{tabular}

GDS: geriatric depression scale; CSF: cerebrospinal fluid; CDR: clinical dementia rating; DM: diabetes mellitus; MMSE: mini-mental state examination; AD: Alzheimer's disease; AchEI: anticholinesterase inhibitor; and pts: patients.

found significantly increased protein carbonyl levels in $\mathrm{AD}$ [47].

Regarding nitrated protein that represents protein peroxidation, there is no consistency among different research groups on assessing nitrated protein level in AD. Although direct measurement from brain tissue postmortem reveals consistently significantly higher nitrated protein in AD [19, 43,49 ], only two studies demonstrate significantly higher CSF nitrate protein level in $\mathrm{AD}[46,48]$. Two other studies report no difference between $\mathrm{AD}$ and controls $[18,50]$.

\section{Conclusions}

Most studies show that serum markers of lipid peroxidation are elevated in Alzheimer's disease. However, there is insufficient evidence to justify the routine use of biomarkers as predictors of severity or outcome in AD.

\section{Conflict of Interests}

The authors declare that they have no competing interests. 


\section{Acknowledgment}

The authors wish to thank Dr. Gene Alzona Nisperos for editing and reviewing the paper for English language considerations.

\section{References}

[1] M. W. Weiner, D. P. Veitch, P. S. Aisen et al., "The Alzheimer's disease neuroimaging initiative: a review of papers published since its inception," Alzheimer's and Dementia, vol. 8, no. 1, supplement, pp. S1-S68, 2012.

[2] J. A. Hardy and G. A. Higgins, "Alzheimer's disease: the amyloid cascade hypothesis," Science, vol. 256, no. 5054, pp. 184-185, 1992.

[3] M. A. Smith, C. A. Rottkamp, A. Nunomura, A. K. Raina, and G. Perry, "Oxidative stress in Alzheimer's disease," Biochimica et Biophysica Acta, vol. 1502, no. 1, pp. 139-144, 2000.

[4] L. Migliore, I. Fontana, F. Trippi et al., "Oxidative DNA damage in peripheral leukocytes of mild cognitive impairment and $\mathrm{AD}$ patients," Neurobiology of Aging, vol. 26, no. 5, pp. 567-573, 2005.

[5] Á. Casado, M. Encarnación López-Fernández, M. Concepción Casado, and R. De La Torre, "Lipid peroxidation and antioxidant enzyme activities in vascular and alzheimer dementias," Neurochemical Research, vol. 33, no. 3, pp. 450-458, 2008.

[6] J. A. Serra, R. O. Domínguez, E. S. De Lustig et al., "Parkinson's disease is associated with oxidative stress: comparison of peripheral antioxidant profiles in living Parkinson's, Alzheimer's and vascular dementia patients," Journal of Neural Transmission, vol. 108, no. 10, pp. 1135-1148, 2001.

[7] D. O. Cristalli, N. Arnal, F. A. Marra, M. J. T. De Alaniz, and C. A. Marra, "Peripheral markers in neurodegenerative patients and their first-degree relatives," Journal of the Neurological Sciences, vol. 314, no. 1-2, pp. 48-56, 2012.

[8] M. Carantoni, G. Zuliani, M. R. Munari, K. D’Elia, E. Palmieri, and R. Fellin, "Alzheimer disease and vascular dementia: relationships with fasting glucose and insulin levels," Dementia and Geriatric Cognitive Disorders, vol. 11, no. 3, pp. 176-180, 2000.

[9] A. J. Sinclair, A. J. Bayer, J. Johnston, C. Warner, and S. R. Maxwell, "Altered plasma antioxidant status in subjects with Alzheimer's disease and vascular dementia," International Journal of Geriatric Psychiatry, vol. 13, no. 12, pp. 840-845, 1998.

[10] C. J. Foy, A. P. Passmore, M. D. Vahidassr, I. S. Young, and J. T. Lawson, "Plasma chain-breaking antioxidants in Alzheimer's disease, vascular dementia and Parkinson's disease," QJM, vol. 92, no. 1, pp. 39-45, 1999.

[11] Y. Ihara, T. Hayabara, K. Sasaki et al., "Free radicals and superoxide dismutase in blood of patients with Alzheimer's disease and vascular dementia," Journal of the Neurological Sciences, vol. 153, no. 1, pp. 76-81, 1997.

[12] I. Guidi, D. Galimberti, S. Lonati et al., "Oxidative imbalance in patients with mild cognitive impairment and Alzheimer's disease," Neurobiology of Aging, vol. 27, no. 2, pp. 262-269, 2006.

[13] P. Bermejo, P. Gomez-Serranillos, J. Santos, E. Pastor, P. Gil, and S. Martin-Aragon, "Determination of malonaldehyde in Alzheimer's disease: a comparative study of high-performance liquid chromatography and thiobarbituric acid test," Gerontology, vol. 43, no. 4, pp. 218-222, 1997.

[14] M. Y. Aksenov, M. V. Aksenova, D. A. Butterfield, J. W. Geddes, and W. R. Markesbery, "Protein oxidation in the brain in Alzheimer's disease," Neuroscience, vol. 103, no. 2, pp. 373-383, 2001.
[15] I. Bourdel-Marchasson, M.-C. Delmas-Beauviex, E. Peuchant et al., "Antioxidant defences and oxidative stress markers in erythrocytes and plasma from normally nourished elderly Alzheimer patients," Age and Ageing, vol. 30, no. 3, pp. 235-241, 2001.

[16] P. Mecocci, M. Cristina Polidori, A. Cherubini et al., "Lymphocyte oxidative DNA damage and plasma antioxidants in Alzheimer disease," Archives of Neurology, vol. 59, no. 5, pp. 794798, 2002.

[17] S. Aldred, S. Bennett, and P. Mecocci, "Increased low-density lipoprotein oxidation, but not total plasma protein oxidation, in Alzheimer's disease," Clinical Biochemistry, vol. 43, no. 3, pp. 267-271, 2010.

[18] M. A. Korolainen and T. Pirttilä, "Cerebrospinal fluid, serum and plasma protein oxidation in Alzheimer's disease," Acta Neurologica Scandinavica, vol. 119, no. 1, pp. 32-38, 2009.

[19] A. Castegna, V. Thongboonkerd, J. B. Klein, B. Lynn, W. R. Markesberyl, and D. A. Butterfield, "Proteomic identification of nitrated proteins in Alzheimer's disease brain," Journal of Neurochemistry, vol. 85, no. 6, pp. 1394-1401, 2003.

[20] H. Aybek, F. Ercan, D. Aslan, and T. Şahiner, "Determination of malondialdehyde, reduced glutathione levels and APOE4 allele frequency in late-onset Alzheimer's disease in Denizli, Turkey," Clinical Biochemistry, vol. 40, no. 3-4, pp. 172-176, 2007.

[21] R. Ozcankaya and N. Delibas, "Malondialdehyde, superoxide dismutase, melatonin, iron, copper, and zinc blood concentrations in patients with Alzheimer disease: cross-sectional study," Croatian Medical Journal, vol. 43, no. 1, pp. 28-32, 2002.

[22] J. A. Serra, R. O. Domínguez, E. R. Marschoff, E. M. Guareschi, A. L. Famulari, and A. Boveris, "Systemic oxidative stress associated with the neurological diseases of aging," Neurochemical Research, vol. 34, no. 12, pp. 2122-2132, 2009.

[23] F. Sinem, K. Dildar, E. Gökhan, B. Melda, Y. Orhan, and M. Filiz, "The serum protein and lipid oxidation marker levels in Alzheimer's disease and effects of cholinesterase inhibitors and antipsychotic drugs therapy," Current Alzheimer Research, vol. 7, no. 5, pp. 463-469, 2010.

[24] L. L. Torres, N. B. Quaglio, G. T. De Souza et al., "Peripheral oxidative stress biomarkers in mild cognitive impairment and Alzheimer's disease," Journal of Alzheimer's Disease, vol. 26, no. 1, pp. 59-68, 2011.

[25] M. C. Polidori and P. Mecocci, "Plasma susceptibility to free radical-induced antioxidant consumption and lipid peroxidation is increased in very old subjects with Alzheimer disease," Journal of Alzheimer's Disease, vol. 4, no. 6, pp. 517-522, 2002.

[26] M. Padurariu, A. Ciobica, L. Hritcu, B. Stoica, W. Bild, and C. Stefanescu, "Changes of some oxidative stress markers in the serum of patients with mild cognitive impairment and Alzheimer's disease," Neuroscience Letters, vol. 469, no. 1, pp. 610, 2010.

[27] S. Martín-Aragón, P. Bermejo-Bescós, J. Benedí et al., "Metalloproteinase's activity and oxidative stress in mild cognitive impairment and Alzheimer's disease," Neurochemical Research, vol. 34, no. 2, pp. 373-378, 2009.

[28] M. C. Puertas, J. M. Martínez-Martos, M. P. Cobo, M. P. Carrera, M. D. Mayas, and M. J. Rami'rez-Expósito, "Plasma oxidative stress parameters in men and women with early stage Alzheimer type dementia," Experimental Gerontology, vol. 47, no. 8, pp. 625-630, 2012.

[29] M. A. Fernandes, M. T. Proenca, A. J. Nogueira et al., "Influence of apolipoprotein E genotype on blood redox status of 
Alzheimer's disease patients," International Journal of Molecular Medicine, vol. 4, no. 2, pp. 179-186, 1999.

[30] C. Galbusera, M. Facheris, F. Magni et al., "Increased susceptibility to plasma lipid peroxidation in Alzheimer disease patients," Current Alzheimer Research, vol. 1, no. 2, pp. 103-109, 2004.

[31] I. Ceballos-Picot, M. Merad-Boudia, A. Nicole et al., "Peripheral antioxidant enzyme activities and selenium in elderly subjects and in dementia of Alzheimer's type-place of the extracellular glutathione peroxidase," Free Radical Biology and Medicine, vol. 20, no. 4, pp. 579-587, 1996.

[32] M. Gironi, A. Bianchi, A. Russo et al., "Oxidative imbalance in different neurodegenerative diseases with memory impairment," Neurodegenerative Diseases, vol. 8, no. 3, pp. 129-137, 2011.

[33] J. Kalman, I. Dey, S. V. Ilona et al., "Platelet membrane fluidity and plasma malondialdehyde levels in Alzheimer's demented patients with and without family history of dementia," Biological Psychiatry, vol. 35, no. 3, pp. 190-194, 1994.

[34] L. T. McGrath, B. M. McGleenon, S. Brennan, D. McColl, S. McIlroy, and A. P. Passmore, "Increased oxidative stress in Alzheimer's disease as assessed with 4-hydroxynonenal but not malondialdehyde," QJM, vol. 94, no. 9, pp. 485-490, 2001.

[35] M. A. Sekler, J. M. Jiménez, L. Rojo et al., "Cognitive impairment and Alzheimer's disease: links with oxidative stress and cholesterol metabolism," Neuropsychiatric Disease and Treatment, vol. 4, no. 4, pp. 715-722, 2008.

[36] C. Jeandel, M. B. Nicolas, F. Dubois, F. Nabet-Belleville, F. Penin, and G. Cuny, "Lipid peroxidation and free radical scavengers in Alzheimer's disease," Gerontology, vol. 35, no. 5-6, pp. 275-282, 1989.

[37] M. Schrag, C. Mueller, M. Zabel et al., "Oxidative stress in blood in Alzheimer's disease and mild cognitive impairment: a metaanalysis," Neurobiology of Disease, vol. 59, pp. 100-110, 2013.

[38] M. Uno, K. T. Kitazato, K. Nishi, H. Itabe, and S. Nagahiro, "Raised plasma oxidised LDL in acute cerebral infarction," Journal of Neurology Neurosurgery and Psychiatry, vol. 74, no. 3, pp. 312-316, 2003.

[39] C. E. Teunissen, J. De Vente, H. W. M. Steinbusch, and C. De Bruijn, "Biochemical markers related to Alzheimer's dementia in serum and cerebrospinal fluid," Neurobiology of Aging, vol. 23, no. 4, pp. 485-508, 2002.

[40] Z.-Y. Cai, Y. Yan, L. Yan et al., "Serum level of MMP-2, MMP9 and Ox-LDL in Alzheimer's disease with hyperlipoidemia," Journal of Medical Colleges of PLA, vol. 22, no. 6, pp. 352-356, 2007.

[41] P. Bermejo, S. Martín-Aragón, J. Benedí et al., "Peripheral levels of glutathione and protein oxidation as markers in the development of Alzheimer's disease from Mild Cognitive Impairment," Free Radical Research, vol. 42, no. 2, pp. 162-170, 2008.

[42] C. C. Conrad, P. L. Marshall, J. M. Talent, C. A. Malakowsky, J. Choi, and R. W. Gracy, "Oxidized proteins in Alzheimer's plasma," Biochemical and Biophysical Research Communications, vol. 275, no. 2, pp. 678-681, 2000.

[43] R. Sultana, H. F. Poon, J. Cai et al., "Identification of nitrated proteins in Alzheimer's disease brain using a redox proteomics approach," Neurobiology of Disease, vol. 22, no. 1, pp. 76-87, 2006.

[44] J. Choi, C. A. Malakowsky, J. M. Talent, C. C. Conrad, and R. W. Gracy, "Identification of oxidized plasma proteins in Alzheimer's disease," Biochemical and Biophysical Research Communications, vol. 293, no. 5, pp. 1566-1570, 2002.

[45] M. A. Korolainen, T. A. Nyman, P. Nyyssönen, E. S. Hartikainen, and T. Pirttilä, "Multiplexed proteomic analysis of oxidation and concentrations of cerebrospinal fluid proteins in Alzheimer disease," Clinical Chemistry, vol. 53, no. 4, pp. 657665, 2007.

[46] N. Ahmed, U. Ahmed, P. J. Thornalley, K. Hager, G. Fleischer, and G. Münch, "Protein glycation, oxidation and nitration adduct residues and free adducts of cerebrospinal fluid in Alzheimer's disease and link to cognitive impairment," Journal of Neurochemistry, vol. 92, no. 2, pp. 255-263, 2005.

[47] A. Castegna, M. Aksenov, M. Aksenova et al., "Proteomic identification of oxidatively modified proteins in Alzheimer's disease brain. Part I: creatine kinase BB, glutamine synthase, and ubiquitin carboxy-terminal hydrolase L-1," Free Radical Biology and Medicine, vol. 33, no. 4, pp. 562-571, 2002.

[48] H. Tohgi, T. Abe, K. Yamazaki, T. Murata, E. Ishizaki, and C. Isobe, "Alterations of 3-nitrotyrosine concentration in the cerebrospinal fluid during aging and in patients with Alzheimer's disease," Neuroscience Letters, vol. 269, no. 1, pp. 52-54, 1999.

[49] K. Hensley, M. L. Maidt, Z. Yu, H. Sang, W. R. Markesbery, and R. A. Floyd, "Electrochemical analysis of protein nitrotyrosine and dityrosine in the Alzheimer brain indicates region-specific accumulation," Journal of Neuroscience, vol. 18, no. 20, pp. 8126 8132, 1998.

[50] H. Ryberg, A.-S. Söderling, P. Davidsson, K. Blennow, K. Caidahl, and L. I. Persson, "Cerebrospinal fluid levels of free 3nitrotyrosine are not elevated in the majority of patients with amyotrophic lateral sclerosis or Alzheimer's disease," Neurochemistry International, vol. 45, no. 1, pp. 57-62, 2004.

[51] M. C. Polidori, W. Stahl, O. Eichler, I. Niestroj, and H. Sies, "Profiles of antioxidants in human plasma," Free Radical Biology and Medicine, vol. 30, no. 5, pp. 456-462, 2001.

[52] T.-S. Kim, C.-U. Pae, S.-J. Yoon et al., "Decreased plasma antioxidants in patients with Alzheimer's disease," International Journal of Geriatric Psychiatry, vol. 21, no. 4, pp. 344-348, 2006.

[53] J. K. Maesaka, G. Wolf-Klein, J. M. Piccione, and C. M. $\mathrm{Ma}$, "Hypouricemia, abnormal renal tubular urate transport, and plasma natriuretic factor(s) in patients with Alzheimer's disease," Journal of the American Geriatrics Society, vol. 41, no. 5, pp. 501-506, 1993.

[54] P. Rinaldi, M. C. Polidori, A. Metastasio et al., "Plasma antioxidants are similarly depleted in mild cognitive impairment and in Alzheimer's disease," Neurobiology of Aging, vol. 24, no. 7, pp. 915-919, 2003.

[55] C. Ruggiero, A. Cherubini, F. Lauretani et al., "Uric acid and dementia in community-dwelling older persons," Dementia and Geriatric Cognitive Disorders, vol. 27, no. 4, pp. 382-389, 2009.

[56] D. J. Schretlen, A. B. Inscore, H. A. Jinnah, V. Rao, B. Gordon, and G. D. Pearlson, "Serum uric acid and cognitive function in community-dwelling older adults," Neuropsychology, vol. 21, no. 1, pp. 136-140, 2007.

[57] L. Iuliano, R. Monticolo, G. Straface et al., "Vitamin E and enzymatic/oxidative stress-driven oxysterols in amnestic mild cognitive impairment subtypes and Alzheimer's disease," Journal of Alzheimer's Disease, vol. 21, no. 4, pp. 1383-1392, 2010.

[58] F. J. Jiménez-Jiménez, F. de Bustos, J. A. Molina et al., "Cerebrospinal fluid levels of alpha-tocopherol (vitamin E) in Alzheimer's disease," Journal of Neural Transmission, vol. 104, no. 6-7, pp. 703-710, 1997. 
[59] Z. Zaman, S. Roche, P. Fielden, P. G. Frost, D. C. Niriella, and A. C. D. Cayley, "Plasma concentrations of vitamins A and E and carotenoids in Alzheimer's disease," Age and Ageing, vol. 21, no. 2, pp. 91-94, 1992.

[60] M. Glasø, G. Nordbø, L. Diep, and T. Bøhmer, "Reduced concentrations of several vitamins in normal weight patients with late-onset dementia of the Alzheimer type without vascular disease," Journal of Nutrition, Health and Aging, vol. 8, no. 5, pp. 407-413, 2004.

[61] M. Sano, C. Ernesto, R. G. Thomas et al., "A controlled trial of selegiline, alpha-tocopherol, or both as treatment for Alzheimer's disease," The New England Journal of Medicine, vol. 336, no. 17, pp. 1216-1222, 1997.

[62] S. Riviere, I. Birlouez-Aragon, F. Nourhashémi, and B. Vellas, "Low plasma vitamin C in Alzheimer patients despite an adequate diet," International Journal of Geriatric Psychiatry, vol. 13, no. 11, pp. 749-754, 1998.

[63] C. A. von Arnim, F. Herbolsheimer, T. Nikolaus et al., "Dietary antioxidants and dementia in a population-based case-control study among older people in South Germany," Journal of Alzheimer's Disease, vol. 31, no. 4, pp. 717-724, 2012.

[64] S. Schippling, A. Kontush, S. Arlt et al., "Increased lipoprotein oxidation in Alzheimer's disease," Free Radical Biology and Medicine, vol. 28, no. 3, pp. 351-360, 2000.

[65] A. Cherubini, C. Ruggiero, M. C. Polidori, and P. Mecocci, "Potential markers of oxidative stress in stroke," Free Radical Biology and Medicine, vol. 39, no. 7, pp. 841-852, 2005.

[66] N. Tabet, D. Mantle, Z. Walker, and M. Orrell, "Vitamins, trace elements, and antioxidant status in dementia disorders," International Psychogeriatrics, vol. 13, no. 3, pp. 265-275, 2001.

[67] J. Snaedal, J. Kristinsson, S. Gunnarsdóttir, Á. Ólafsdóttir, M. Baldvinsson, and T. Jóhannesson, "Copper, ceruloplasmin and superoxide dismutase in patients with Alzheimer's disease. A case-control study," Dementia and Geriatric Cognitive Disorders, vol. 9, no. 5, pp. 239-242, 1998.

[68] H. Kharrazi, A. Vaisi-Raygani, Z. Rahimi, H. Tavilani, M. Aminian, and T. Pourmotabbed, "Association between enzymatic and non-enzymatic antioxidant defense mechanism with apolipoprotein E genotypes in Alzheimer disease," Clinical Biochemistry, vol. 41, no. 12, pp. 932-936, 2008.

[69] R. Perrin, S. Briancon, C. Jeandel et al., "Blood activity of $\mathrm{Cu} / \mathrm{Zn}$ superoxide dismutase, glutathione peroxidase and catalase in Alzheimer's disease: a case-control study," Gerontology, vol. 36, no. 5-6, pp. 306-313, 1990.

[70] L. Rossi, R. Squitti, P. Pasqualetti et al., "Red blood cell copper, zinc superoxide dismutase activity is higher in Alzheimer's disease and is decreased by D-penicillamine," Neuroscience Letters, vol. 329, no. 2, pp. 137-140, 2002.

[71] M. E. De Leo, S. Borrello, M. Passantino et al., "Oxidative stress and overexpression of manganese superoxide dismutase in patients with Alzheimer's disease," Neuroscience Letters, vol. 250, no. 3, pp. 173-176, 1998.

[72] M. P. Bowes, J. A. Zivin, G. R. Thomas, H. Thibodeaux, and S. C. Fagan, "Acute hypertension, but not thrombolysis, increases the incidence and severity of hemorrhagic transformation following experimental stroke in rabbits," Experimental Neurology, vol. 141, no. 1, pp. 40-46, 1996.

[73] I. Baldeiras, I. Santana, M. T. Proença et al., "Peripheral oxidative damage in mild cognitive impairment and mild Alzheimer's disease," Journal of Alzheimer's Disease, vol. 15, no. 1, pp. 117-128, 2008.
[74] A. Nunomura, T. Tamaoki, N. Motohashi et al., "The earliest stage of cognitive impairment in transition from normal aging to alzheimer disease is marked by prominent RNA oxidation in vulnerable neurons," Journal of Neuropathology and Experimental Neurology, vol. 71, no. 3, pp. 233-241, 2012.

[75] G. P. Paraskevas, E. Kapaki, G. Libitaki, C. Zournas, I. Segditsa, and C. Papageorgiou, "Ascorbate in healthy subjects, amyotrophic lateral sclerosis and Alzheimer's disease," Acta Neurologica Scandinavica, vol. 96, no. 2, pp. 88-90, 1997.

[76] H. Vural, H. Demirin, Y. Kara, I. Eren, and N. Delibas, "Alterations of plasma magnesium, copper, zinc, iron and selenium concentrations and some related erythrocyte antioxidant enzyme activities in patients with Alzheimer's disease," Journal of Trace Elements in Medicine \& Biology, vol. 24, no. 3, pp. 169173,2010 

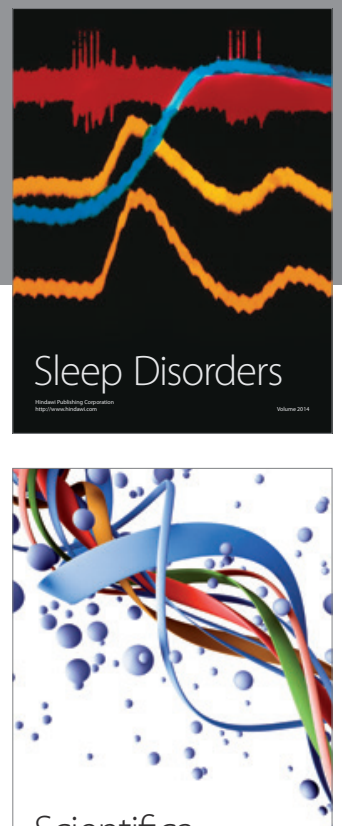

Scientifica
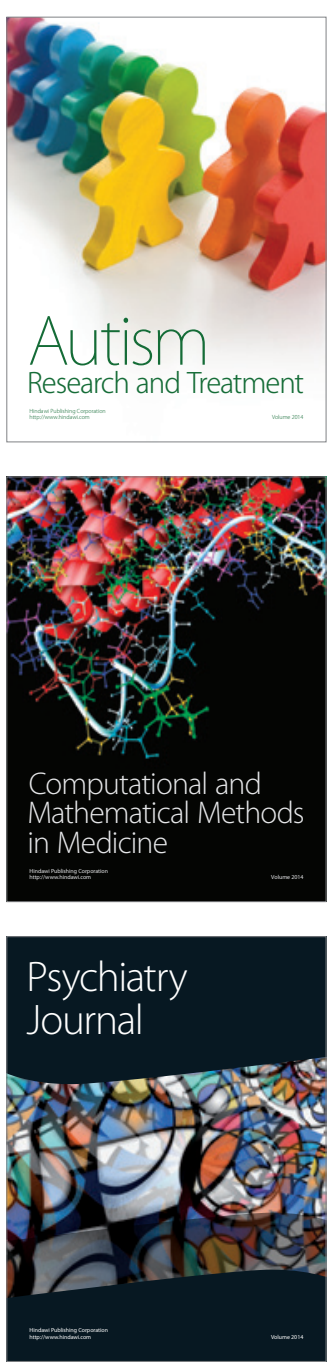
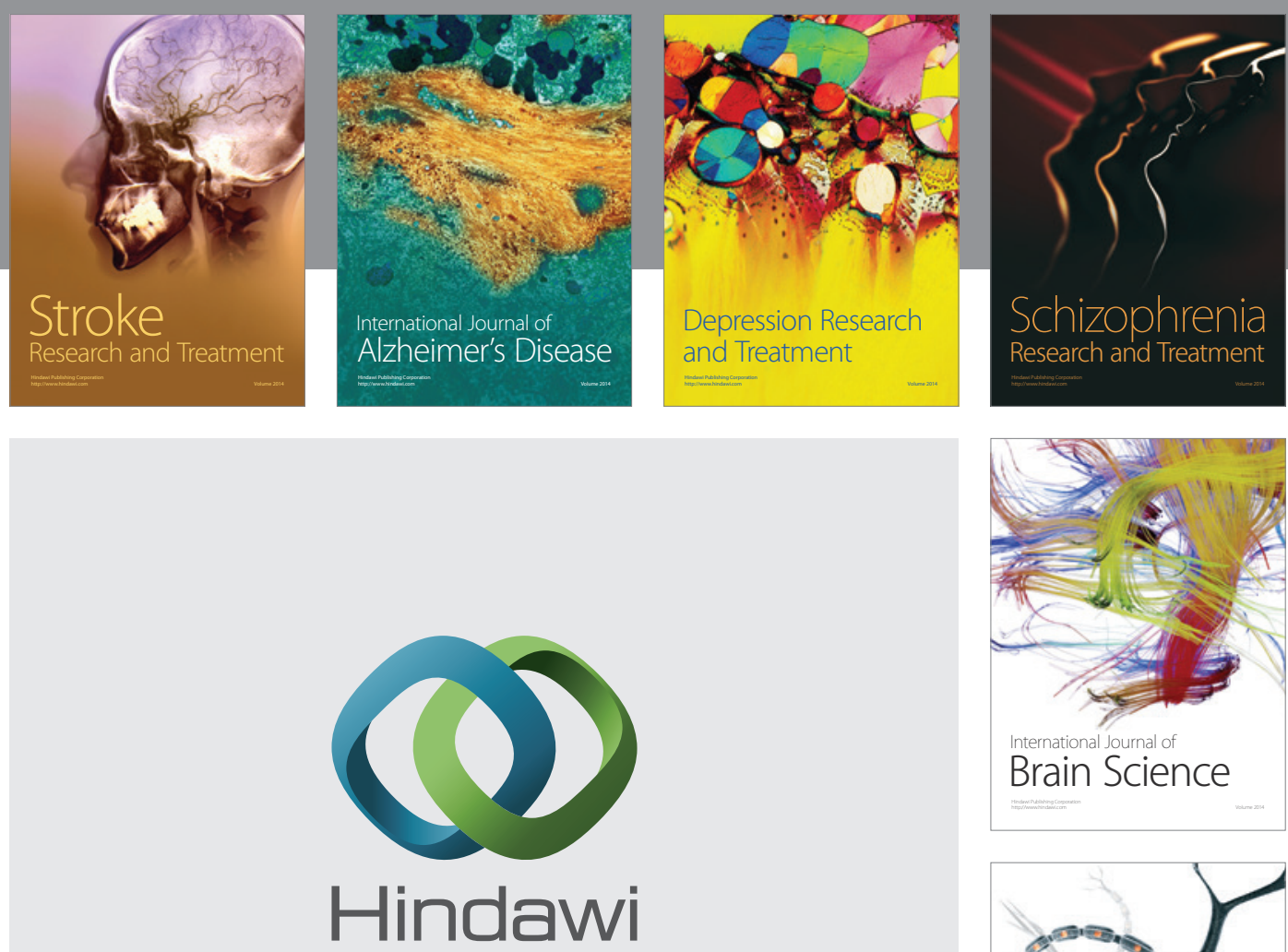

Submit your manuscripts at

http://www.hindawi.com
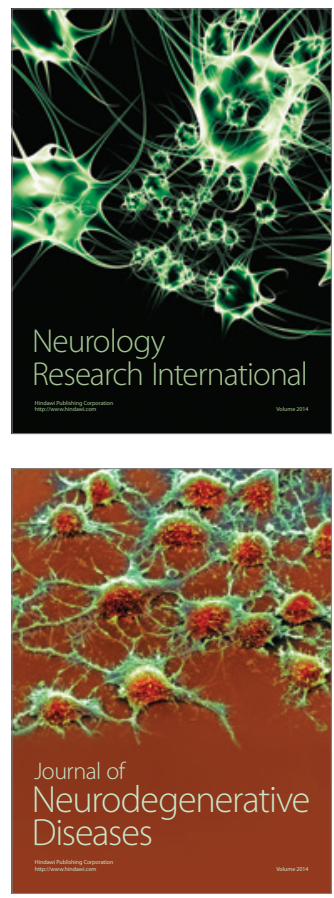

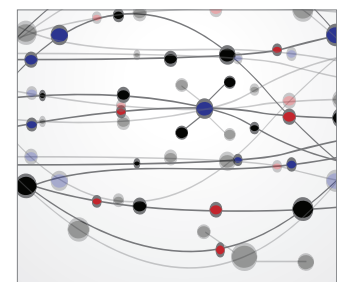

The Scientific World Journal
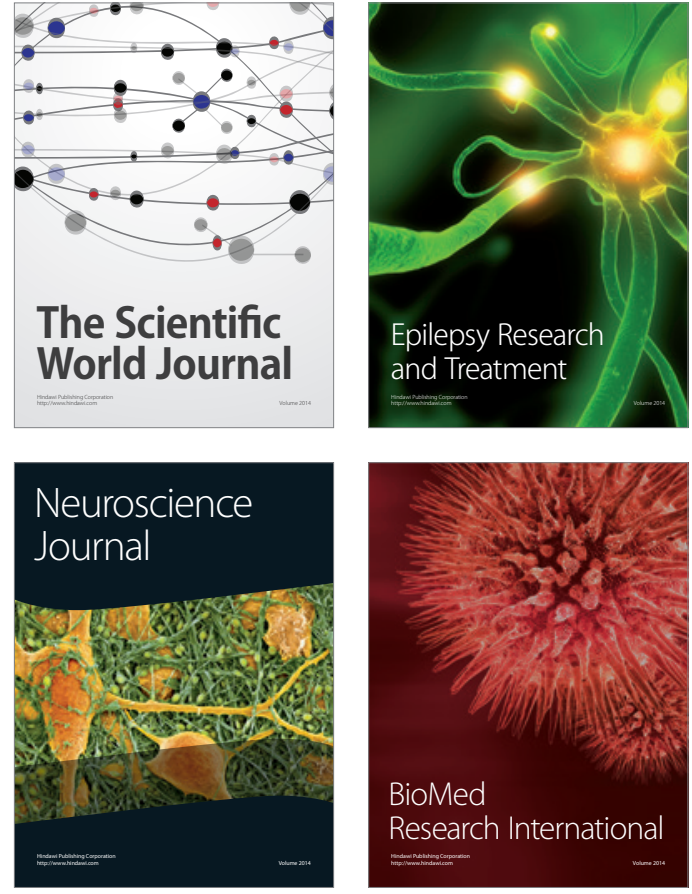

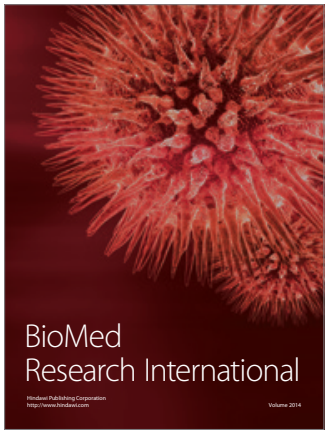

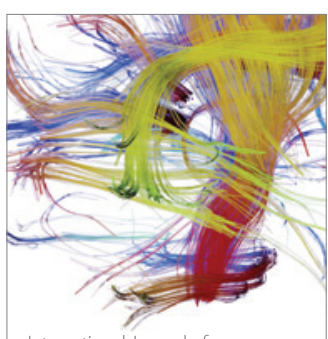

Brain Science

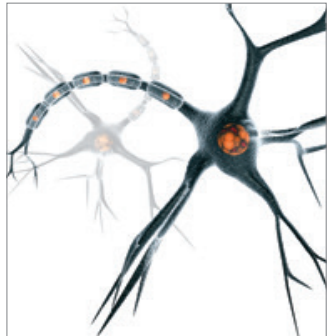

Neural Plasticity
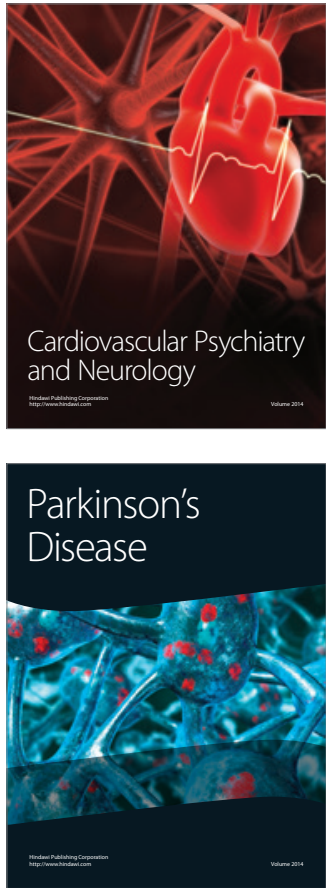